\title{
Canopy structure explains the relationship between photosynthesis and sun-induced chlorophyll fluorescence in crops
}

\author{
Benjamin Dechant ${ }^{1}$, Youngryel Ryu ${ }^{1 *}$, Grayson Badgley ${ }^{2}$, Yelu Zeng ${ }^{2}$, Joseph A. Berry ${ }^{2}$, Yongguang \\ Zhang ${ }^{3}$, Yves Goulas ${ }^{4}$, Zhaohui $\mathrm{Li}^{3}$, Qian Zhang ${ }^{3}$, Minseok Kang ${ }^{5}$, $\mathrm{Ji} \mathrm{Li}^{3}$, Ismaël Moya ${ }^{4}$ \\ ${ }^{1}$ Department of Landscape Architecture and Rural Systems Engineering, Seoul National University, \\ South Korea \\ ${ }^{2}$ Department of Global Ecology, Carnegie Institution for Science, Stanford, USA \\ ${ }^{3}$ International Institute for Earth System Sciences, Jiangsu Provincial Key Laboratory of Geographic \\ Information Science and Technology, Nanjing University, Nanjing, China \\ ${ }^{4}$ Dynamic Meteorology Laboratory, Ecole Polytechnique, Palaiseau, France \\ ${ }^{5}$ National Center for AgroMeteorology, Seoul, South Korea \\ Corresponding author: yryu@snu.ac.kr
}

THIS IS A NON-PEER REVIEWED PREPRINT SUBMITTED TO EARTHARXIV 


\begin{abstract}
Remote sensing of far-red sun-induced chlorophyll fluorescence (SIF) has emerged as an important tool for studying gross primary productivity (GPP) at the global scale. However, the relationship between SIF and GPP at the canopy scale lacks a clear mechanistic explanation. This is largely due to the poorly characterized role of the relative contributions from canopy structure and leaf physiology to the variability of the top-of-canopy, observed SIF signal. In particular, the effect of the canopy structure beyond light absorption is that only a fraction $\left(f_{\text {esc }}\right)$ of the SIF emitted from all leaves in the canopy can escape from the canopy due to the strong scattering of near-infrared radiation. We combined rice, wheat and corn canopy-level in-situ datasets to study how the physiological and structural components of SIF individually relate to measures of photosynthesis. At seasonal time scales, we found a considerably strong positive correlation $\left(R^{2}=0.4-0.6\right)$ of $f_{\text {esc }}$ to the seasonal dynamics of the photosynthetic light use efficiency ( $L_{U} E_{p}$ ), while the estimated physiological SIF yield was almost entirely uncorrelated to LUE $E_{p}$ both at seasonal and diurnal time scales, with the partial exception of wheat. Consistent with these findings, the canopy structure and radiation component of $\mathrm{SIF}$, defined as the product of APAR and $\mathrm{f}_{\mathrm{esc}}$, explained the relationship of observed SIF to GPP and even outperformed GPP estimation based on observed SIF at two of the three sites investigated. These results held for both half-hourly and daily mean values. In contrast, the total emitted SIF, obtained by normalizing observed SIF for $\mathrm{f}_{\mathrm{esc}}$, improved only the relationship to APAR but considerably decreased the correlation to GPP for all three crops. Our findings demonstrate the dominant role of canopy structure in the SIF-GPP relationship and establish a strong, mechanistic link between the near-infrared reflectance of vegetation $\left(N I R_{V}\right)$ and the relevant canopy structure information contained in the SIF signal. These insights are expected to be useful in improving remote sensing based GPP estimates.
\end{abstract}

Keywords: sun-induced chlorophyll fluorescence, light use efficiency, photosynthesis, near-infrared reflectance of vegetation, NIRv, escape fraction, canopy scattering, canopy structure 


\section{Introduction}

Sun-induced chlorophyll fluorescence (SIF) is increasingly used as a proxy for gross primary productivity (GPP) at large scales (Mohammed et al., 2019; Ryu et al., 2019). SIF is an optical signal emitted in the spectral range $650-850 \mathrm{~nm}$ from chlorophyll a molecules in vegetation (Lichtenthaler et al., 1986). The far-red part of SIF at about $760 \mathrm{~nm}$, on which our study strongly concentrates, has a well-documented, empirical relationship to estimate GPP at both the site (Sun et al., 2017; Yang et al., 2015; Yongguang Zhang et al., 2016), regional (Guanter et al., 2014; Yongguang Zhang et al., 2018; Yao Zhang et al., 2016), and global scales (Frankenberg et al., 2011; Guanter et al., 2012; Joiner et al., 2011). The precise reason for the SIF-GPP relationship at the canopy scale, however, lacks a clear mechanistic explanation. This is mostly due to an insufficient understanding of the relative contributions of leaf physiological and canopy structure effects to SIF and how the physiological and structural components of SIF relate to photosynthetic light use efficiency. Therefore, it is helpful to revisit the basic processes and equations relevant for SIF and GPP as the basis for more closely examining the possible mechanisms that might underlie their strong empirical correspondence.

SIF and GPP differ in one important respect with regard to their fundamental processes. GPP is related to leaf-level gas exchange processes and therefore, observed top-of-canopy GPP is simply the cumulated GPP of all leaves, as gases that might temporarily accumulate in the canopy eventually will diffuse out of it. Far-red SIF, however, is an optical signal in the near-infrared spectral range, where light is strongly scattered by leaves allowing only a certain fraction to escape the canopy (Knyazikhin et al., 2013; Yang and van der Tol, 2018; Zeng et al., 2019). Therefore, the top-of-canopy SIF as observed from tower, airborne or satellite platforms is not simply the cumulative signal of SIF emitted by all leaves but contains an extra term quantifying the effect of canopy scattering. While reabsorption of SIF photons is a strong effect for red SIF around $690 \mathrm{~nm}$, this effect can be neglected for the far-red SIF at $760 \mathrm{~nm}$ (Yang and van der Tol, 2018), which we exclusively consider in this study. Both SIF and GPP can be understood conceptually in the light use efficiency framework originally introduced for net primary productivity (Monteith, 1972; Monteith and Moss, 1977). Thus, for GPP we have

$$
\mathrm{GPP}=\mathrm{APAR} \times \mathrm{LUE}_{\mathrm{P}}
$$


where GPP is defined as the product of the photosynthetically active radiation (PAR) absorbed by the canopy (APAR) and the photosynthetic light use efficiency of the canopy (LUE $E_{\mathrm{P}}$. Similarly, for SIF as observed above the canopy $\left(\mathrm{SIF}_{\text {obs }}\right)$, we have

$$
\mathrm{SIF}_{\mathrm{obs}}=\mathrm{APAR} \times \Phi_{\mathrm{F}} \times \mathrm{f}_{\mathrm{esc}}
$$

where $\Phi_{F}$ is the physiological SIF emission yield of the whole canopy and $f_{\text {esc }}$ is the fraction of all SIF photons, emitted from all leaves, that escape from the canopy (Guanter et al., 2014; Zeng et al., 2019). When comparing the basic equations for GPP and SIF, $\Phi_{F}$ corresponds to the LUE term and $f_{\text {esc }}$ is the extra term that quantifies the effects of canopy scattering.

Several experimental and modelling studies demonstrated that APAR is the dominant factor in the variability of $\mathrm{SIF}_{\mathrm{obs}}$ and the relationship of $\mathrm{SIF}_{\mathrm{obs}}$ to GPP at sub-daily temporal resolution (Li et al., 2020; Miao et al., 2018; Wieneke et al., 2018; K. Yang et al., 2018; Yongguang Zhang et al., 2016). However, the separate contributions of $\Phi_{\mathrm{F}}$ and $\mathrm{f}_{\mathrm{esc}}$ have not been quantified so far to the best of our knowledge.

Modeling studies from as early as 2012 recognized that $f_{\text {esc }}$ plays a significant role in controlling the amount of SIF observed at top-of-canopy (Fournier et al., 2012). In terms of functional dependencies, $\mathrm{f}_{\text {esc }}$ has been shown to respond strongly to changes in both leaf area index (LAI) (Fournier et al., 2012; Yang and van der Tol, 2018) and leaf angle distribution (Du et al., 2017; Migliavacca et al., 2017; Zeng et al., 2019). More generally, it follows from the results of Zeng et al. (2019) that any canopy structure parameter that influences the near-infrared reflectance can have a considerable effect on $\mathrm{f}_{\text {esc }}$. In particular, apart from LAl and leaf angle distribution, the clumping index is expected to play an important role for $f_{\text {esc }}$ (Zeng et al., 2019).

Despite the advances in our theoretical understanding of $f_{e s c}$, little work has gone into understanding what, if any, role $\mathrm{f}_{\text {esc }}$ has in explaining the SIF-GPP relationship. Instead, the effects of $f_{\text {esc }}$ for relating SIF to GPP have largely been ignored in the SIF literature (e.g. Guanter et al., 2014; Wieneke et al., 2016; Yang et al., 2017, 2015). However, a number of more recent studies have reported direct evidence of distorting effects of $f_{\text {esc }}$ on the SIF $_{\text {obs }}$-APAR relationship (Du et al., 2017; Liu et al., 2018) and indirect evidence of how $f_{\text {esc }}$ affects the $S_{1} F_{o b s}-$ GPP relationships using both process-based modelling and observations (Migliavacca et al., 2017). While it is clear from the literature and Eqn. 2 that $\mathrm{f}_{\text {esc }}$ partially obscures the $\Phi_{\mathrm{F}}$ signal, there is no decisive conclusion so far 
whether $f_{\text {esc }}$ is helpful or detrimental for GPP estimation. Two apparently opposing views on this question are presented in more detail in the following paragraphs.

Several studies have argued that canopy structure effects on $\mathrm{SIF}_{\mathrm{obs}}$ should be corrected for the purpose of optimal GPP estimation based on the assumption that $\Phi_{\mathrm{F}}$ has a positive relationship to LUE $_{\mathrm{p}}$ (Du et al., 2017; Liu et al., 2018; Yang and van der Tol, 2018). In terms of quantitative evidence, however, such reasoning has been largely based on the improvement of the APAR-SIF relationship when accounting for canopy structure (Du et al., 2017; Liu et al., 2018). However, in considering only the SIF-APAR relationship, these studies are insufficient for evaluating the possible role that $f_{\text {esc }}$ might have in explaining the SIF-GPP relationship. In particular, as GPP estimation has been the ultimate goal of most SIF research, GPP needs to be explicitly considered in the analysis. Logically, an improvement in the APAR-SIF relationships could very well go together with a degradation of the SIFGPP relationship; the better the relationship of SIF to APAR, the smaller the variation of the efficiency term SIF/APAR but LUE $=$ GPP/APAR actually represents a special case of an efficiency term with considerable variation. Moreover, we are unaware of any experimental or modelling studies that explicitly considered the relationship between $\Phi_{F}$ and $L U E_{P}$ at the canopy scale. Instead, several studies have evaluated the relationship between $\operatorname{LUE}_{\mathrm{p}}$ and the joint influence of canopy physiology $\left(\Phi_{\mathrm{F}}\right)$ and canopy structure $\left(\mathrm{f}_{\mathrm{esc}}\right)$, as obtained by dividing canopy escaping SIF $\mathrm{Fbs}_{\text {s }}$ by APAR (Li et al., 2020; Eqn. 2; Miao et al., 2018; Wieneke et al., 2018, 2016; K. Yang et al., 2018; Yang et al., 2015). Wieneke et al. (2018) and Li et al. (2020) attempted to empirically correct for canopy structure effects in the apparent SIF yield by dividing with the MTVI2 vegetation index that was shown to be related to LAI. However, such an approach not only assumes a linear relationship between LAI and $f_{\text {esc }}$ but also neglects the potentially strong impact of temporally varying leaf angle distribution and clumping.

Interestingly, the reasoning that $\Phi_{\mathrm{F}}$ underlies the SIF-GPP relationship is not well supported by several strands within the existing SIF literature. At the leaf scale, $\Phi_{F}$ is known both to vary less than $\mathrm{LUE}_{\mathrm{p}}$ and to be nonlinearly related to $\mathrm{LUE}_{\mathrm{p}}$ in light response curves (Gu et al., 2019; van der Tol et al., 2014). Similarly, in situ measurements have shown low seasonal correlation of $\Phi_{F}$ and $L_{E} E_{P}$ (Goulas et al., 2017). At the canopy level, these findings are supported by several experimental studies which have shown higher correlation of $\mathrm{SIF}_{\text {obs }}$ to APAR compared with $\mathrm{SIF}_{\text {obs }}$ to GPP (Miao et al., 2018; Wieneke et al., 2018; K. Yang et al., 2018). 
In contrast to the $\Phi_{\mathrm{F}}$-based reasoning above highlighting the role of leaf physiology, (Badgley et al., 2019,2017 ) have argued that it is precisely the canopy structure that explains the SIF $_{\text {obs }}-$ GPP relationship. Their reasoning is based on the NIR reflectance of vegetation (NIRV), a multi-spectral reflectance-based measurement that is strongly linear with both $\mathrm{SIF}_{\mathrm{obs}}$ and GPP at large spatial and long temporal scales. However, the $\mathrm{NIR}_{\mathrm{V}}$-GPP relationship has so far not been tested with groundlevel spectral observations at the shorter time scales that include diurnal variations of both APAR and $L_{U} E_{P}$. Nor have previous studies of $\mathrm{NIR}_{V}$ gone beyond documenting the empirical $\mathrm{NIR}_{V}-\mathrm{GPP}$ relationship. The strong connection between the NIR reflectance and $f_{\text {esc }}$ (Liu et al., 2018; Yang and van der Tol, 2018; Zeng et al., 2019) hints at potential links between $f_{\text {esc }}$ and LUE $E_{p}$ which could be investigated more directly.

For the sake of clarity and simplicity, the two opposing views presented above can be condensed into the following two hypotheses:

( $\left.H_{\text {phys }}\right)$ dominance of leaf physiology:

$\Phi_{F}$ is correlated to $L_{U E}$, while $f_{\text {esc }}$ is not and, therefore, the product of APAR and $\Phi_{F}$ outperforms $\mathrm{SIF}_{\text {obs }}$ for GPP estimation.

$\left(\mathrm{H}_{\text {struc }}\right)$ dominance of canopy structure:

$f_{\text {esc }}$ is correlated to $L_{U}$, while $\Phi_{F}$ is not and, therefore, the product of APAR and $f_{\text {esc }}$ outperforms $\mathrm{SIF}_{\text {obs }}$ for GPP estimation.

Our goal in this study is to test which of these two hypotheses is better supported by observations. To do this, we applied the $f_{\text {esc }}$ estimation approach of Zeng et al. (2019) to three independently collected datasets in rice, wheat and corn, which consist of continuous measurements covering the whole crop growing season. As the above hypotheses represent the two extreme cases, it is clear that the truth might actually lie somewhere in between the two. Furthermore, the results are expected to depend on the time scale as canopy structure changes that affect $f_{\text {esc }}$, which mostly occur at the seasonal time scale, while physiological changes that might affect $\Phi_{\mathrm{F}}$ occur over the course of individual days as well as over the growing season (Dechant et al., 2019). Our analysis therefore considers these different time scales 


\section{Materials and methods}

\subsection{Theoretical framework: decomposing far-red SIF into its mechanistic parts}

The basic equation for canopy-level $\mathrm{SIF}_{\mathrm{obs}}$ in terms of its separate mechanistic components was given in the introduction (Eqn. 2). For convenience in later sections, we define $L_{U E}=S_{F} F_{\text {obs }} / A P A R$ as the apparent light use efficiency of SIF in analogy to the definition of photosynthetic light use efficiency, $L_{U E}=$ GPP/APAR. The escape fraction of whole canopy far-red SIF emissions can be estimated from $\mathrm{NIR}_{\mathrm{V}}$ and fPAR following the approach outlined by Zeng et al. (2019):

$$
\mathrm{f}_{\mathrm{esc}} \approx \frac{\mathrm{NIR}}{\mathrm{fPAR}}
$$

where NIR is the product of NIR reflectance and the NDVI (Badgley et al., 2017). Zeng et al. (2019) demonstrated the good performance of Eqn. 3 with comprehensive radiative transfer simulations as well as supporting evidence from satellite observations. In particular, they showed that $f_{\text {esc }}$ derived from NIR performs well even for sparsely vegetated canopies and is minimally affected by changes in soil brightness. When fPAR, PAR and NIR observations are available, in addition to SIF obs, we can combine Eqns. 2 and 3 to calculate the following two SIF-related variables. First, the product of APAR and $\Phi_{F}$, which represents the total emitted SIF and includes signals emitted from the leaf adaxial and abaxial parts, and is therefore a mixture of the canopy radiation absorption and the physiological emission efficiency (Fig. 1). Second, the product of APAR and $f_{\text {esc }}$, which represents a combined canopy structure and radiation factor and includes both absorption and scattering aspects of the canopy structure (Fig. 1). While $f_{\text {esc }}$ is a pure canopy structure property for far-red SIF, APAR is, in principle, not only affected by canopy structure but also by leaf pigments. dfs However, the impact of leaf pigments on APAR was found to be marginal and strongly dominated by canopy structure characteristics such as leaf angle distribution, clumping and LAI (Luo et al., 2019). Only when distinguishing total vs. green APAR would we expect to see an impact of leaf pigments on certain parts of our analysis, which is discussed in detail in section 4.4. 


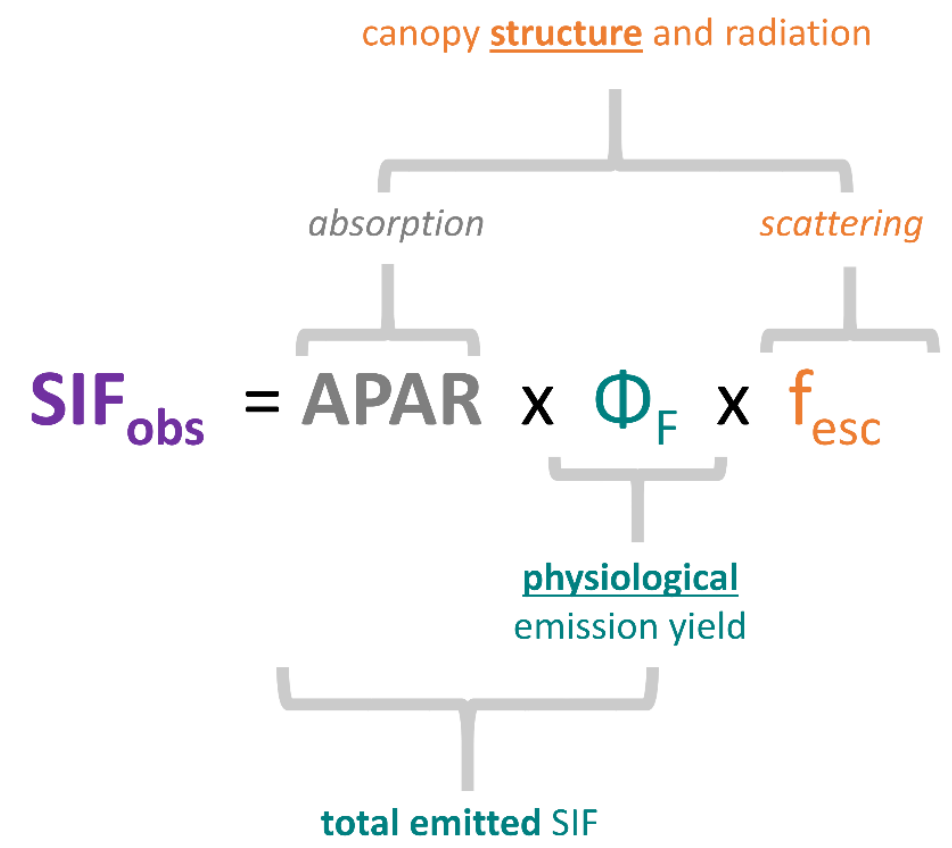

Figure 1: Overview of the conceptual meaning of relevant SIF-related variables. All terms are given at the canopy scale. The light absorption part (APAR) is composed of the fraction of absorbed photosynthetically active radiation, fPAR, and the level of incoming PAR. $\Phi_{\mathrm{F}}$ is the physiological SIF emission yield from all leaves in the canopy and $\mathrm{f}_{\mathrm{esc}}$ is the fraction of emitted SIF that escapes from the canopy. Colors for physiological, structural and combined terms are kept consistently in the presentation of all results for easier visual orientation.

We first conducted analyses focusing on $\Phi_{\mathrm{F}}$ and $\mathrm{f}_{\mathrm{esc}}$ to directly examine the roles of canopy scattering and physiological processes. In a second step, we investigated the relationships of SIF obs, $\mathrm{APAR} \times \Phi_{\mathrm{F}}$ and APAR $\times f_{\text {esc }}$ to GPP. This second step is important as it quantifies the contributions of $\Phi_{F}$ or $f_{\text {esc }}$ combined with APAR to the estimation of GPP (Fig. 1). All relevant SIF-related variables as well as $\Phi_{\mathrm{F}}$ and $\mathrm{f}_{\text {esc }}$ can be derived from Eqns. 2 and 3 as shown in Table 1. In particular, it is important that APAR $\times f_{\text {esc }}$ is estimated using only $\mathrm{NIR}_{\mathrm{V}}$ and PAR without any contribution from $\mathrm{SIF}_{\text {obs }}$. 
Table 1: Overview of relevant SIF-related variables and their components in terms of observation or estimation/calculation method and the relevant reference to previous literature or equations in this manuscript. Observed and estimated variables are highlighted with a gray shaded background. PAR is photosynthetically active radiation, fPAR is the fraction of PAR absorbed by the canopy, APAR is the absorbed PAR, SIF obs is the canopy-level observed, far-red sun-induced chlorophyll fluorescence, NIR is the near-infrared reflectance of vegetation, NDVI the normalized difference vegetation index, $f_{\text {esc }}$ is the fraction of SIF emitted from all leaves in the canopy escaping the canopy, APAR $\times \Phi_{F}$ is the total emitted SIF, APAR $\times f_{\text {esc }}$ is the structure and radiation component, and $\Phi_{F}$ is the physiological SIF emission yield of the canopy. Obs., calc., and estim. Indicate observed, calculated and estimated, respectively. Canopy reflectance is abbreviated as 'refl.' and the wavelength range over which the average was calculated is indicated in units of nanometer.

\begin{tabular}{|c|c|c|c|c|}
\hline variable & $\begin{array}{l}\text { obs./ } \\
\text { calc. } \\
\text { /esti } \\
\text { m. }\end{array}$ & $\begin{array}{c}\text { conceptual } \\
\text { meaning/definition }\end{array}$ & $\begin{array}{l}\text { estimation } \\
\text { method }\end{array}$ & $\begin{array}{c}\text { reference/eqn. } \\
\text { /section }\end{array}$ \\
\hline PAR & obs. & - & - & - \\
\hline APAR & obs. & - & - & - \\
\hline RED & obs. & refl. at $600-650 \mathrm{~nm}$ & - & - \\
\hline NIR & obs. & refl. at $800-850 \mathrm{~nm}$ & - & - \\
\hline SIF $_{\text {obs }}$ & obs. & APAR $\times \Phi_{\mathrm{F}} \times \mathrm{f}_{\mathrm{esc}}$ & - & Eqn. 2 \\
\hline NDVI & calc. & $\frac{N I R-R E D}{N I R+R E D}$ & - & Rouse et al. (1973) \\
\hline $\mathrm{NIR}_{V}$ & calc. & NDVI×NIR & - & $\begin{array}{l}\text { Badgley, Field and Berry } \\
\text { (2017) }\end{array}$ \\
\hline fPAR & calc. & PAR/APAR & - & - \\
\hline$\Phi_{\mathrm{F}} \times \mathrm{f}_{\mathrm{esc}}$ & calc. & $\mathrm{SIF}_{\text {obs }} / \mathrm{APAR}$ & - & Eqn. 2, section 2.1 .1 \\
\hline$f_{\text {esc }}$ & estim & - & $\mathrm{NIR}_{\mathrm{V}} / \mathrm{fPAR}$ & Eqn. 3, Zeng et al. (2019) \\
\hline APAR $\times f_{\text {esc }}$ & estim & - & $\mathrm{NIR}_{V} \times \mathrm{PAR}$ & Eqn. 3 \\
\hline$\Phi_{\mathrm{F}}$ & estim & - & $\mathrm{SIF}_{\text {obs }} /\left(\mathrm{NIR}_{\mathrm{V}} \times \mathrm{PAR}\right.$ & Eqns. 2, 3 \\
\hline $\operatorname{APAR} \times \Phi_{F}$ & estim & - & $\mathrm{fPAR} \times \mathrm{SIF}_{\text {obs }} / \mathrm{NIR}_{\mathrm{V}}$ & Eqns. 2, 3 \\
\hline
\end{tabular}

\subsection{In-situ data sets}

Three in-situ data sets were combined for the analysis. The data sets differ not only in terms of crop type but also in terms of geographical location, instruments used, observation geometry, and retrieval method used to estimate $\mathrm{SIF}_{\mathrm{obs}}$. An overview is given in Table 3 and more detailed descriptions are provided in the following subsections. Half-hourly data from a single growing season for each crop 
were used. All sites had in situ observations of APAR and high spectral resolution instruments for SIF retrieval.

Table 3: Overview of the three field datasets with a focus on SIF observations. For rice, wheat and corn the field of view, sensor height and estimated footprint diameter, SIF retrieval method and spectral resolution (full width at half maximum, FWHM), the acquisition frequency, the number of available half-hourly observations and observation days the geographic location and the key literature references are shown. Furthermore the photosynthetic pathway and the values used for flux partitioning ('flux part.') are indicated. In each column, the outlying characteristic is highlighted in bold font. The SIF retrieval methods include the singular vector decomposition (SVD), the spectral fitting method (SFM) and a modified version of the Fraunhofer line depth method (nFLD) as used by Goulas et al. (2017). For the hemispheric field-of-view configuration in the rice paddy, the footprint diameter is given as range from the cumulative $50 \%$ to $80 \%$ of the total footprint. The whole row for wheat is shaded in grey for easier visual distinction between the different rows.

\begin{tabular}{|c|c|c|c|c|c|c|c|c|}
\hline $\begin{array}{l}\text { Crop } \\
\text { type }\end{array}$ & $\begin{array}{l}\text { Photo- } \\
\text { synthetic } \\
\text { pathway/ } \\
\text { flux part. }\end{array}$ & $\begin{array}{c}\text { Field of } \\
\text { view }\end{array}$ & $\begin{array}{c}\text { Obs. } \\
\text { height } \\
\text { (footprint } \\
\text { diameter) }\end{array}$ & $\begin{array}{l}\text { SIF retr. } \\
\text { method } \\
\text { (FWHM) }\end{array}$ & $\begin{array}{c}\text { Acqui- } \\
\text { sition } \\
\text { frequency }\end{array}$ & $\begin{array}{l}\text { No. of } \\
\text { obs. } \\
\text { (30min } \\
\text { /days) }\end{array}$ & $\begin{array}{l}\text { Lat. }\left({ }^{\circ} \mathrm{N}\right) / \\
\text { Long. }\left({ }^{\circ} \mathrm{E}\right)\end{array}$ & $\begin{array}{l}\text { Literature } \\
\text { Reference }\end{array}$ \\
\hline Rice & $\begin{array}{c}\text { C3/ } \\
\text { night }\end{array}$ & $\begin{array}{l}\text { Hemi- } \\
\text { spheric }\end{array}$ & $\begin{array}{c}5 \mathrm{~m} \\
(20-40 \mathrm{~m})\end{array}$ & $\begin{array}{c}\text { SVD } \\
(0.17 \mathrm{~nm})\end{array}$ & $1 / \min$ & $\begin{array}{l}911 \\
/ 62\end{array}$ & $\begin{array}{l}38.2013 / \\
127.2506\end{array}$ & $\begin{array}{l}\text { K. Yang et } \\
\text { al. (2018) }\end{array}$ \\
\hline Wheat & $\begin{array}{l}\text { C3/ } \\
\text { day }\end{array}$ & Nadir & $\begin{array}{c}20.5 \mathrm{~m} \\
(2 \mathrm{~m})\end{array}$ & $\begin{array}{c}\text { nFLD } \\
(0.5 \mathrm{~nm})\end{array}$ & $60 / \mathrm{min}$ & $\begin{array}{l}633 \\
/ 49\end{array}$ & $\begin{array}{c}43.9175 / \\
4.8797\end{array}$ & $\begin{array}{l}\text { Goulas et } \\
\text { al. (2017) }\end{array}$ \\
\hline Corn & $\begin{array}{c}\text { C4/ } \\
\text { night }\end{array}$ & Nadir & $\begin{array}{c}10 \mathrm{~m} \\
(4.4 \mathrm{~m})\end{array}$ & $\begin{array}{c}\text { SFM } \\
(0.17 \mathrm{~nm})\end{array}$ & $0.5 / \mathrm{min}$ & $\begin{array}{l}769 \\
/ 57\end{array}$ & $\begin{array}{l}34.5199 / \\
115.5916\end{array}$ & $\begin{array}{l}\text { Li et al. } \\
\text { (2020) }\end{array}$ \\
\hline
\end{tabular}

\subsubsection{Rice}

The rice paddy site is located in Cheorwon, South Korea $\left(38.2013^{\circ} \mathrm{N}, 127.2506^{\circ} \mathrm{E}\right)$ and is part of the national eddy flux network, KoFlux (Huang et al., 2018). Oryza sativa L. ssp. Japonica is grown in rows each year there, with a maximum canopy height of $70 \mathrm{~cm}$ and maximum LAl of 6 in the 2016 growing season that lasted from April 29 to September 3. Measurements instruments are operated by Seoul National University and the National Center for Agro Meteorology. An eddy covariance system consisting of a three-dimensional sonic anemometer (Model CSAT3, Campbell Scientific Inc., Logan, UT, USA) and a closed-path infrared gas analyzer (Model LI-7200, LI-COR Inc., Lincoln, NE, USA) was used to measure $\mathrm{CO}_{2}$ fluxes. Net $\mathrm{CO}_{2}$ flux partitioning into gross primary production (GPP) and ecosystem respiration was conducted according to the night time-based method (Reichstein et al., 
2005). SIF was monitored with a very high spectral resolution instrument (full width at half maximum, FWHM $=0.17 \mathrm{~nm}$, QEpro, Ocean Optics, Dunedin, FL, USA) and a fiber switch to measure up- and downwelling irradiances in sequence (K. Yang et al., 2018; X. Yang et al., 2018). The singular vector decomposition (SVD) method (Guanter et al., 2013) was used for SIF retrieval of data acquired every minute and average over 30 minutes. A fixed integration time was used for all measurements. Canopy reflectance in the visible-near-infrared spectral region (VIS-NIR) was monitored with two lower resolution instruments (FWHM $\approx 4 \mathrm{~nm}$, Jaz, Ocean Optics, Dunedin, FL, USA) which simultaneously observed up- and downwelling radiation fluxes. Both the SIF and canopy reflectance systems were operated in bi-hemispheric field-of-view configurations positioned about $5 \mathrm{~m}$ above the rice canopy throughout the whole growing season. This corresponds to an effective footprint size of $40 \mathrm{~m}$ diameter when considering the area that contributes $80 \%$ of the total signal (Marcolla and Cescatti, 2017). Regular calibration was performed for both SIF and canopy reflectance systems using a calibration light source (HL-2000-Cal, Ocean Optics, Dunedin, FL, USA). FPAR was continuously monitored at three sampling locations using an automated, low-cost observation system based on LED sensors (Kim et al., 2019) but had to be gap-filled with PROSAIL (Jacquemoud et al., 2009; Jacquemoud and Baret, 1990) simulation using observed input data. For this, effects of diffuse radiation where taken into account by weighting the PROSAIL outputs corresponding to cloudy and sunny sky conditions with the measured fraction of diffuse and direct PAR. The data was acquired in the year 2016. A more detailed description of the rice paddy site and the methods used can be found in K. Yang et al. (2018).

\subsubsection{Wheat}

The wheat field is located close to Avignon in southeastern France $\left(43.9175^{\circ} \mathrm{N}, 4.8797^{\circ} \mathrm{E}\right)$ and is operated by INRA ('Institut National de la Recherche Agronomique'). Winter wheat (Triticum turgidum ssp. Durum) was sown on November 2009 and harvested in mid June 2010. The wheat is grown in rows and had a maximum canopy height of $86 \mathrm{~cm}$ and maximum LAl of about 7 (Goulas et al., 2017). The site is also part of CarboEurope (Dolman et al., 2006) which provided the eddy flux data. The eddy covariance system consists of a three-dimensional sonic anemometer (Model 81000, R.M. Young Company, Traverse City, MI, USA) and an open path infrared gas analyzer (Model LI-7500, LI-COR Inc.). Flux partitioning was done based on day time values (Kowalski et al., 2003). SIF and canopy 
reflectance was observed with the TriFLEX instrument that consists of separate spectrometers for measurements of SIF and VIS-NIR hyperspectral reflectance (Daumard et al., 2010). The spectrometer for SIF observations has a high spectral resolution (FWHM $=0.5 \mathrm{~nm}$ ) while the broadband reflectance is observed at lower resolution (FWHM $=2 \mathrm{~nm}$ ). The TriFLEX instrument was mounted on a crane at $21 \mathrm{~m}$ above ground, was operated at nadir observation angle and has a narrow field of view resulting in a footprint diameter of about $2 \mathrm{~m}$ (Goulas et al., 2017). In contrast to the system in the rice paddy, downwelling solar irradiance was observed using a white reference panel. SIF was retrieved from high frequency observations (about $1 \mathrm{~Hz}$ ) using a modified Fraunhofer Line Depth (FLD) method that is described in detail in the corresponding references (Daumard et al., 2010; Goulas et al., 2017) and then averaged over 30 minute periods. fPAR was continuously monitored using a network of ten quantum sensors. The data was acquired in the year 2010. More details on the site and the methods used can be found in Daumard et al. (2010) and Goulas et al. (2017).

\subsubsection{Corn}

The corn field is located in Henan province, in central China $\left(34.5199^{\circ} \mathrm{N}, 115.5916^{\circ} \mathrm{E}\right)$ and is also used for growing winter wheat in a rotation system. Corn (Zea mays ssp. Mays) was sown in rows in late June and harvested in early October and had maximum canopy height of $2.5 \mathrm{~m}$ and maximum LAl of about 3.5 (Li et al., 2020). The measurement instruments are operated by Nanjing University and the Farmland Irrigation Institute of the Chinese Academy of Agricultural Sciences. An eddy covariance system consisting of a three-dimensional sonic anemometer (WindMaster Pro, Gill Instruments Limited, Hampshire, UK) and a closed path infrared gas analyzer (LI-7500RS, LI-COR Inc., Lincoln, NE, USA) and was continuously operated. Eddy flux partitioning was done according to the night timebased method of Reichstein et al. (2005). A similar system as in the rice paddy based on the FluoSpec2 design (X. Yang et al., 2018; Yang et al., 2015) was used for SIF retrievals (Ocean Optics QEpro spectrometer with FWHM $=0.17 \mathrm{~nm}$ ). SIF was retrieved from the observations taken every two minutes with a spectral fitting method (SFM) (Meroni et al., 2010; Meroni and Colombo, 2006), before averaging the observations over 30 minute intervals. Integration times were optimized before each measurement. In addition to the high spectral resolution instrument, a lower spectral resolution (FWHM = $1.1 \mathrm{~nm}$ ) spectrometer covering the VIS-NIR range was used to continuously monitor canopy reflectance changes (HR 2000+, Ocean Optics, Dunedin, FL, USA). The latter was also operated with a shutter system to switch between observations of down- and upwelling radiation. In contrast to the 
rice paddy observations, the field of view of both spectrometer systems for upwelling observations was $25^{\circ}$ as bare fibers were used. As the observations were located about $10 \mathrm{~m}$ above the canopy, the measurement footprint circle had a diameter of about $4.4 \mathrm{~m}$ (Li et al., 2020). Radiometric calibration was also conducted with the HL-2000-cal light source (Ocean Optics, Dunedin, FL, USA) for downwelling observations and upwelling observations were calibrated by using a white reference panel (Spectralon, Labsphere, NH, USA) at solar noon under clear sky conditions but this was not automated as for the wheat site. FPAR was continuously monitored with one PAR sensor above and four sensors below the canopy. The data was acquired in the year 2017. More details on the site and the methods used can be found in Li et al. (2020).

\subsection{Data processing and statistical analysis}

For all three crop datasets, only time steps that had measurement values for APAR, $\mathrm{SIF}_{\mathrm{obs}}$ at $760 \mathrm{~nm}$, $\mathrm{NIR}_{V}$ and GPP between 8 am and $4 \mathrm{pm}$ were selected in order to ensure direct comparability of the correlation values for relationships to GPP. For rice and corn, most of the growing season satisfied these criteria, while the wheat site only had data after the green-up phase (supplementary figure Fig. S1). All datasets had some gaps and gap-filled GPP data was not used in any of the presented analyses. For all analyses, we further restricted the data by setting a threshold for fPAR above 0.45 in order to exclude the noisy data in the early growing stage. This affected primarily the rice dataset and was only strictly necessary for analyses of $L_{U} E_{P}, L U E_{F}, f_{e s c}$ and $\Phi_{F}$ but nevertheless also done for the corresponding variables that include APAR to be consistent. In addition to the fPAR threshold, we applied the Hampel outlier filter (Hampel, 1974) to detect and remove several severe outliers in the variables normalized for APAR. The Hampel filter uses the median absolute deviation and an estimate of the standard deviation within the moving window as robust distance metrics. We applied the filter with a conservative threshold parameter value of four and a window length of 12 days. We used the hampel function from the R package pracma (Borchers, 2018) and slightly modified it to accept data with gaps.

For the diurnal correlation and daily mean value calculation, only days with a minimum of five valid data points were selected. Combined with the fPAR threshold, this resulted in 62, 49 and 57 days of data for rice, wheat and corn, respectively (Table 3).

$f_{\text {esc }}$ is reported as unitless quantity, which means that in case of the nadir viewing geometry of wheat and corn, it is equal to the $\pi$ times directional ratio of $\operatorname{SIF}_{\mathrm{obs}}$ to APAR $\times \Phi_{\mathrm{F}}$. This is a similar procedure as chosen for the reflectance factor, that uses a Lambertian surface as reference 
(Schaepman-Strub et al., 2006). This can also be understood in terms of NIR reflectance in Eqn. 3, which is used for the estimation of $f_{\text {esc }}$.

$\mathrm{SIF}_{\mathrm{obs}}$ of the rice dataset was converted from irradiance to radiance units for better comparability with the other two datasets. This was done by a simple division by $\pi$, which can only account for the overall magnitude difference but not the more subtle differences in viewing geometry related to asymmetric angular patterns that differ from a Lambertian surface. For a discussion of these effects, see section 4.4. NIR was calculated from the lower spectral resolution VIS-NIR spectrometers by averaging over the range $800-850 \mathrm{~nm}$ for the NIR band and over $600-650 \mathrm{~nm}$ for the red band (Table 1). The impact of shifting the spectral range of the red band towards the red-edge (e.g. 620-670 nm, 650-700 nm) were evaluated but found to have negligible effects.

All correlation analyses were done based on the Pearson correlation coefficient of which the statistical significance was evaluated with a two-sided t-test at a confidence level of $95 \%$. The squared Pearson correlation coefficient $\left(R^{2}\right)$ is equal to the coefficient of determination in the special case of linear regression with one explanatory variable and an intercept term (Devore, 2011; Kasuya, 2019). Therefore, e.g. the GPP estimation performance of different predictor variables in such linear regression models can be evaluated based on $\mathrm{R}^{2}$. Statistical analysis was done using the programming language $R$ ( $\mathrm{R}$ Core Team, 2012). 


\section{Results}

\subsection{Temporal patterns of and relationships among $f_{e s c}, \Phi_{F}, L U E_{F}$ and $L U E_{P}$}

\subsubsection{Temporal patterns}

We found clear differences in both the seasonal patterns and the degree of diurnal variability of $f_{\text {esc }}$, $\Phi_{F}, L_{F}$ and LUE (Figs. 2, S2). fPAR, $f_{\text {esc }}$ and $L_{\mathrm{F}}$ all appeared to be mainly characterized by considerable seasonal variation (Figs. 2 and S2). $L U E_{P}$ and $\Phi_{F}$, however, showed considerable diurnal variability. In case of $L U E_{p}$, the diurnal variation was superposed to the seasonal changes, while for $\Phi_{\mathrm{F}}$ it seemed to be the main source of variation.

Despite some apparent general patterns for each variable, we found considerable differences between crops. Patterns of fPAR increase during green-up and decrease during senescence were similar for rice and corn while for wheat, where the data for the green-up phase were not available, fPAR was consistently high. For rice and wheat, fPAR reached maximum values of almost 0.9 , while for corn the highest values were around 0.8. Overall, wheat had the lowest diurnal variations for fPAR, corn the strongest variations for some of the days and rice an intermediate level of variability. $f_{\text {esc }}$ of rice showed the strongest increase during green-up and a moderate decreases during senescence; wheat showed only moderate increase during green-up but strong decrease during senescence and in addition showed a small peak around the day of year 130, which was a cloudy period with considerably lower PAR values (Fig. B1b in the appendix and Fig. 3a in Goulas et al., 2017); corn showed only decreasing patterns with a flattening during senescence. Maximum values for $f_{\text {esc }}$ were in around 0.5-0.6 for all crops and minimum values were in the range of 0-0.1. As already mentioned above, $\Phi_{F}$ was seasonally rather constant but wheat showed a clear decrease late in the senescence stage that coincided with a decrease in chlorophyll content (Goulas et al., 2017). For corn, a slight decrease followed by an increase late in the season were observed, while for rice, slight decreases appeared during both the late green-up and senescence. LUE $_{\mathrm{F}}$ overall had similar seasonal patterns as $f_{\text {esc }}$ but also showed some smaller seasonal patterns similar to $\Phi_{F}$ in addition to more diurnal variability from the latter (results not shown). The seasonal patterns for LUE $\mathrm{p}$ were partly masked by strong diurnal variations but decreases during senescence could be observed for all three crops (Fig. $2 \mathrm{j}-\mathrm{I})$. While the decreasing patterns of $L U E_{P}$ for wheat and corn were similar and showed relatively steep slopes, the decrease in rice occurred at an earlier stage and after that $L_{U E}$ was rather stable. 
Increases in $\mathrm{LUE}_{\mathrm{P}}$ during green-up were only clearly evident in the case of rice and to a lesser degree for wheat.

Rice
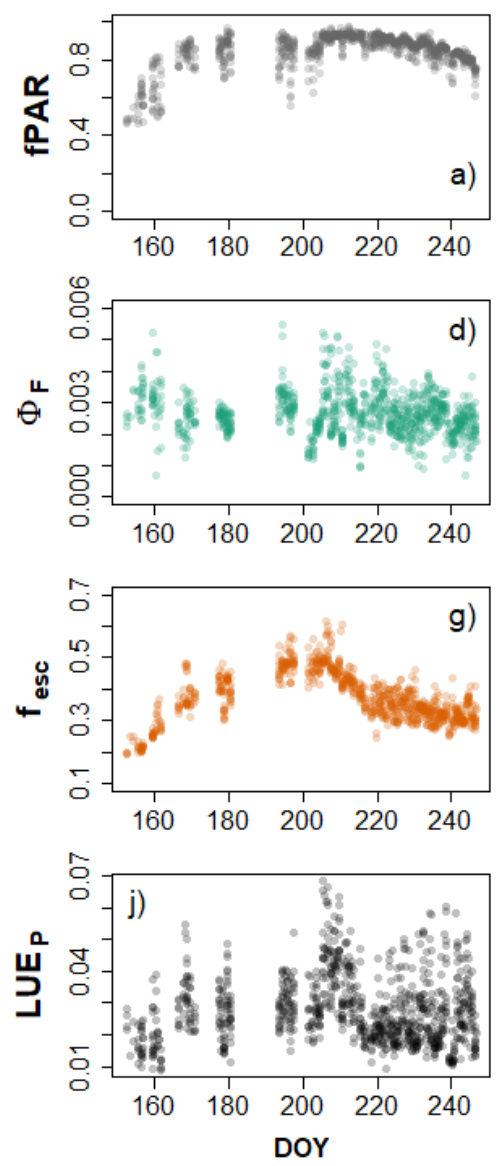

Wheat
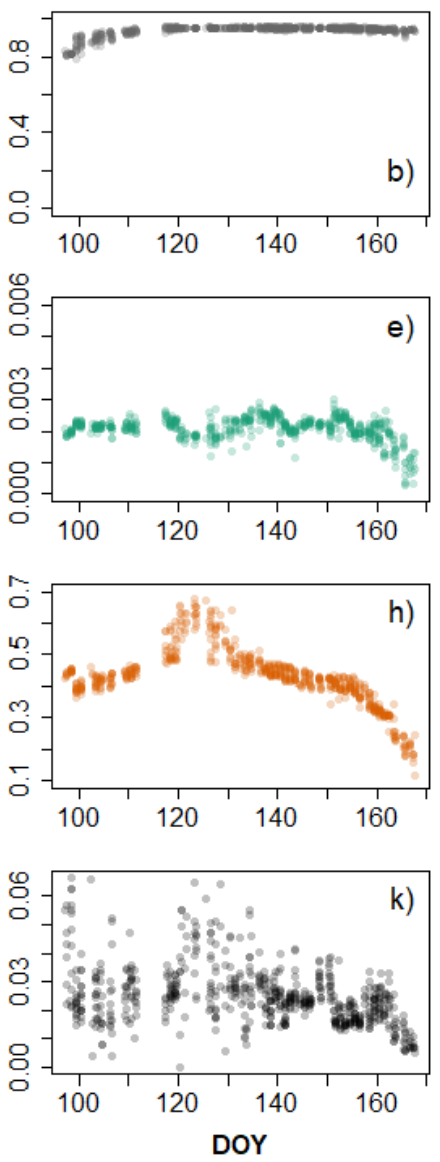

Corn
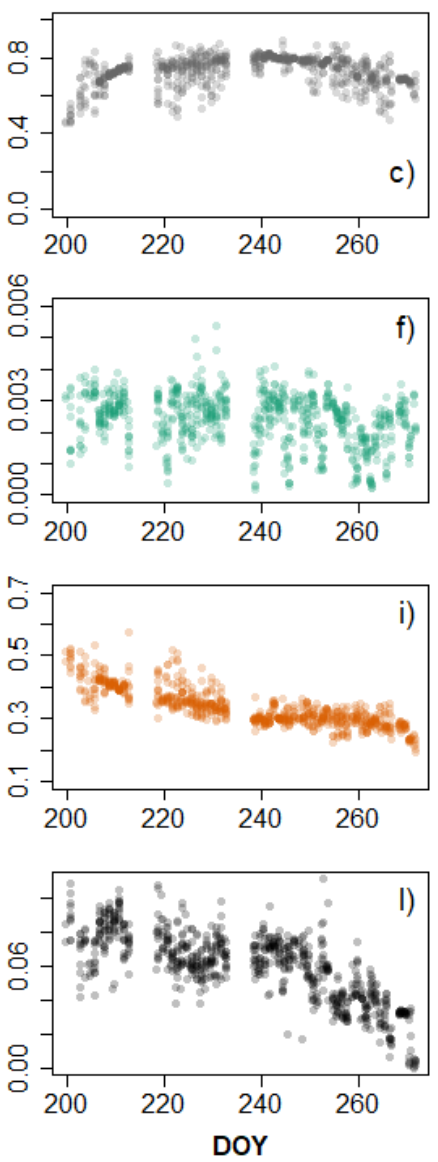

Figure 2: Time series overview of (a-c) fraction of absorbed photosynthetically active radiation (fPAR), (d-f) physiological SIF yield $\left(\Phi_{\mathrm{F}}\right),(g-i)$ escape fraction $\left(\mathrm{f}_{\mathrm{esc}}\right)$, and $(j-l)$ photosynthetic light use efficiency $\left(\right.$ LUE $\left._{\mathrm{P}}\right)$. Half-hourly data are shown as partially transparent, filled circles in order to visualize the density of data points. Time is shown as day of year (doy). While fPAR and $\mathrm{f}_{\mathrm{esc}}$ are unitless quantities, LUE $\mathrm{E}_{\mathrm{P}}$ is shown in units of $\mu \mathrm{mol} \mathrm{CO}_{2} \mathrm{~m}^{-2} \mathrm{~s}^{-1}$, and $\Phi_{\mathrm{F}}$ in units of $\left(\mathrm{mW} \mathrm{m}^{-2} \mathrm{sr}^{-1} \mathrm{~nm}^{-1}\right) /\left(\mu \mathrm{mol}^{-1}\right.$ photons $\mathrm{m}^{-2} \mathrm{~s}^{-1}$ ).

The figure corresponding to Fig. 2 in terms of daily mean values highlighting only the seasonal component of variation and including $\mathrm{LUE}_{\mathrm{F}}$ is shown in the supplementary material (Fig. S1).

\subsubsection{Relationships to $\mathrm{LUE}_{\mathrm{p}}$}


To more directly test our two hypotheses, we built on the qualitative analysis of temporal patterns shown in Fig. 2, by quantifying the correlations of $\Phi_{F}$ and $f_{\text {esc }}$ to $L U E_{p}$. We found that in the relationships to $\mathrm{LUE}_{\mathrm{p}}$, the following pattern of increasing correlation was consistent for all crops and for both half-hourly and daily mean values at the seasonal time scale: $\Phi_{F}<L E_{F}<f_{\text {esc }}$ (Fig. 3 and Fig. B1 in the appendix).

For half-hourly values, i.e. seasonal+diurnal variability, $\Phi_{\mathrm{F}}$ had no correlation to $\mathrm{LUE}_{\mathrm{P}}$ for all three crop types. $f_{\text {esc }}$, in contrast, had significant and moderate correlations, with squared Pearson correlation values $\left(R^{2}\right)$ of $0.28,0.28$ and 0.44 for rice, wheat and corn, respectively. The corresponding values for $L_{U} E_{F}$ were generally on the order of half the value of $f_{e s c}$ (Fig. B1). Overall, $L_{U E} E_{F}$ was most strongly related to $\Phi_{F}$ but wheat was an exception where the correlation of $\mathrm{f}_{\text {esc }}$ was stronger (Fig. S2). $f_{\text {esc }}$ and $\Phi_{F}$ were almost uncorrelated although wheat and corn showed significant but low values $\left(R^{2}\right.$ of 0.14 and 0.06 , respectively). For the sake of completeness, we included full correlation tables between all four efficiency terms in the supplementary material (Fig. S2).

When considering the correlations of $f_{\text {esc }}$ and $\Phi_{F}$ to $L U E_{P}$ for the seasonal variability based on daily mean values, we found that $f_{\text {esc }}$ outperformed $\Phi_{F}$ in all cases but with considerably larger differences for the seasonal variability (Figs. 3, B1). While significant correlations between $\Phi_{F}$ and $\mathrm{LUE}_{\mathrm{p}}$ did not increase much for the seasonal variability compared to the seasonal+diurnal variability (a large increase for rice was not significant), the corresponding $f_{\text {esc }}-$ LUE $_{p}$ correlations strongly increased up to 0.6 for wheat and corn and 0.4 for rice and were highly significant (Fig. 3).

The correlations to $\mathrm{LUE}_{\mathrm{p}}$ for diurnal variability only showed different patterns compared to the seasonal variability for $\Phi_{\mathrm{F}}$ and $\mathrm{f}_{\mathrm{esc}}$. For $\Phi_{\mathrm{F}}$, the correlations based on diurnal variability exceeded the $\mathrm{R}^{2}$ values that included seasonal variability for all three crop types, but were all below 0.2 and considerably higher for wheat than for rice and corn (Fig. B1a). For $\mathrm{f}_{\mathrm{esc}}$, the diurnal correlations were consistently lower than those for seasonal+diurnal variability and seasonal variability, although the differences were smaller for rice (Fig. B1C). 

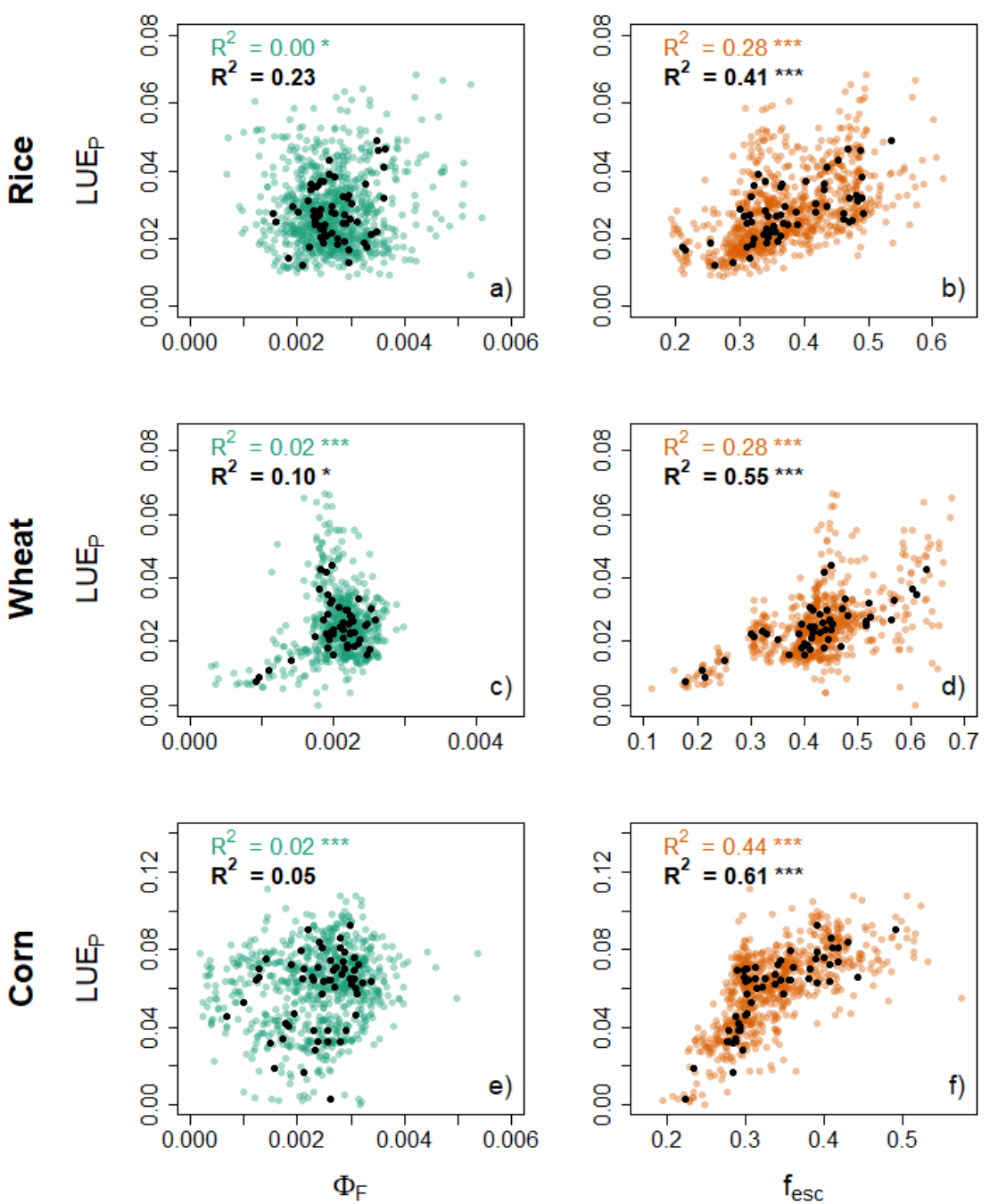

Figure 3: Overview of relationships of physiological SIF yield $\left(\Phi_{\mathrm{F}}\right)$ and the escape fraction $\left(\mathrm{f}_{\mathrm{esc}}\right)$ to photosynthetic light use efficiency (LUE $\left.\mathrm{E}_{\mathrm{p}}\right)$. Results based on either half-hourly or daily mean values at the seasonal scale. Half-hourly data points are shown with partially transparent filled circles in order to indicate point density and corresponding $R^{2}$ values are shown. LUE $E_{p}$ is shown in units of $\mu \mathrm{mol} \mathrm{CO} \mathrm{CO}_{2} \mathrm{~m}^{-2} \mathrm{~s}^{-1}$, and $\Phi_{\mathrm{F}}$ in units of $\left(\mathrm{mW} \mathrm{m}^{-2} \mathrm{~nm}^{-1} \mathrm{sr}^{-1}\right) /\left(\mu \mathrm{mol}\right.$ photons $\left.\mathrm{m}^{-2} \mathrm{~s}^{-1}\right)$. Significance of the

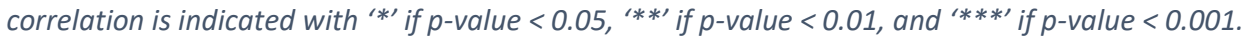

The diurnal variability case was the only one where $L_{U E}$ was not consistently intermediate between $\Phi_{\mathrm{F}}$ and $\mathrm{f}_{\mathrm{esc}}$. In particular, for wheat, $\mathrm{LUE}_{\mathrm{F}}$ was slightly more strongly related to $L U E_{\mathrm{P}}$ than either $\Phi_{\mathrm{F}}$ or $\mathrm{f}_{\mathrm{esc}}$ separately and for rice, $\mathrm{LUE}_{\mathrm{F}}$ had a slightly lower correlation to LUE than $\Phi_{\mathrm{F}}$ (Fig. B1b). 


\subsection{Relationships to GPP and APAR}

The first part of the results focused on the relationships of $\Phi_{F}$ and $f_{e s c}$ to LUE . However, the ultimate goal of most SIF-related research is GPP estimation. Therefore, we investigate the implications of the relationships of $\Phi_{F}$ and $f_{\text {esc }}$ to $L U E_{P}$ for GPP estimation by comparing the relationships of APAR multiplied with $\Phi_{\mathrm{F}}, \mathrm{f}_{\mathrm{esc}}$ or their product to GPP. APAR itself is used as a reference case both as predictor of GPP and as target variable for estimation.

There were clear differences in the GPP estimation performance of $\mathrm{SIF}_{\text {obs }}, \mathrm{APAR} \times \mathrm{f}_{\text {esc }}$, and APAR $\times \Phi_{\mathrm{F}}$, with APAR $\times \mathrm{f}_{\text {esc }}$ having the strongest correlation with GPP (Figs. 4 and 5a). The following pattern of increasing linear correlation to GPP was consistent for all crops and for halfhourly and daily mean values at the seasonal time scale: APAR $\times \Phi_{\mathrm{F}}<\operatorname{SIF}_{\text {obs }} \leq \mathrm{APAR} \times \mathrm{f}_{\text {esc }}$ (Figs. 4 and $5 a)$. APAR $\times f_{\text {esc }}$ strictly outperformed $\mathrm{SIF}_{\text {obs }}$ for rice and corn with $\mathrm{R}^{2}$ values of 0.74 for halfhourly (0.86 for daily mean) and $0.82(0.83)$, respectively, but had almost the same performance for wheat with an $R^{2}$ of $0.52(0.74)$ and $0.51(0.73)$, respectively. APAR $\times \Phi_{F}$ had generally much lower correlations to GPP than $\operatorname{SIF}_{\text {obs }}\left(0.1<\Delta R^{2}<0.2\right.$ for half-hourly data). Overall, differences in $R^{2}$ of $\mathrm{APAR} \times \mathrm{f}_{\mathrm{esc}}$ compared to $\mathrm{SIF}_{\text {obs }}$ were largest for corn, intermediate for rice and smallest for wheat, while the roles of rice and corn were exchanged for the differences between APAR $\times \Phi_{F}$ and APAR $\times$ $f_{\text {esc }}$ (Fig. S3a). While APAR $\times f_{\text {esc }}$ showed a slight tendency to saturate at high values in the case of rice and corn, we did not observe this pattern for wheat (Fig. 4d,h,I). Furthermore, the $\mathrm{SIF}_{\mathrm{obs}}{ }^{-G P P}$ relationship showed clear signs of saturation for corn and wheat but not for rice (Fig. 4c,g,k). For rice and corn, the differences in GPP estimation performance of different predictor variables were mainly caused by deviations from the ideal case of perfect correlation for values in the middle and high part of the GPP range (Fig. 4a-d,i-I). For wheat, however, the deviations from the ideal case was more notable also in the low to middle parts of the GPP range (Fig. 4e-h). Relaxing the fPAR threshold criterion (see section 2.3) did not change the relative GPP estimation performance of APAR $\times \Phi_{F}$, APAR $\times f_{\text {esc }}$, and SIF $F_{o b s}$ and only had marginal effects on the $R^{2}$ values for wheat and corn (results not shown). However, as rice had a prolonged green-up phase resulting in a large number of low GPP values, the performances of predictors for the full dataset without applying the fPAR threshold were considerably higher for all variables $\left(0.1 \leq \Delta R^{2} \leq 0.18\right)$, in particular had an $R^{2}$ value of 0.84 (Fig. S2).

For GPP estimation, the performance rank of APAR compared to SIF-related variables differed for wheat, where APAR performed worst, while the order APAR $\times \Phi_{F}<$ APAR $<$ SIF obs in terms of $\mathrm{R}^{2}$ held 
for rice and corn (Figs. 4 and 5a). The differences between APAR and SIF $_{\text {obs }}$ in terms of absolute increase in $\mathrm{R}^{2}$ were smallest for corn and largest for wheat. An overview of the time series for all GPP predictor variables and all crop types is given in Fig. A1 in the appendix.
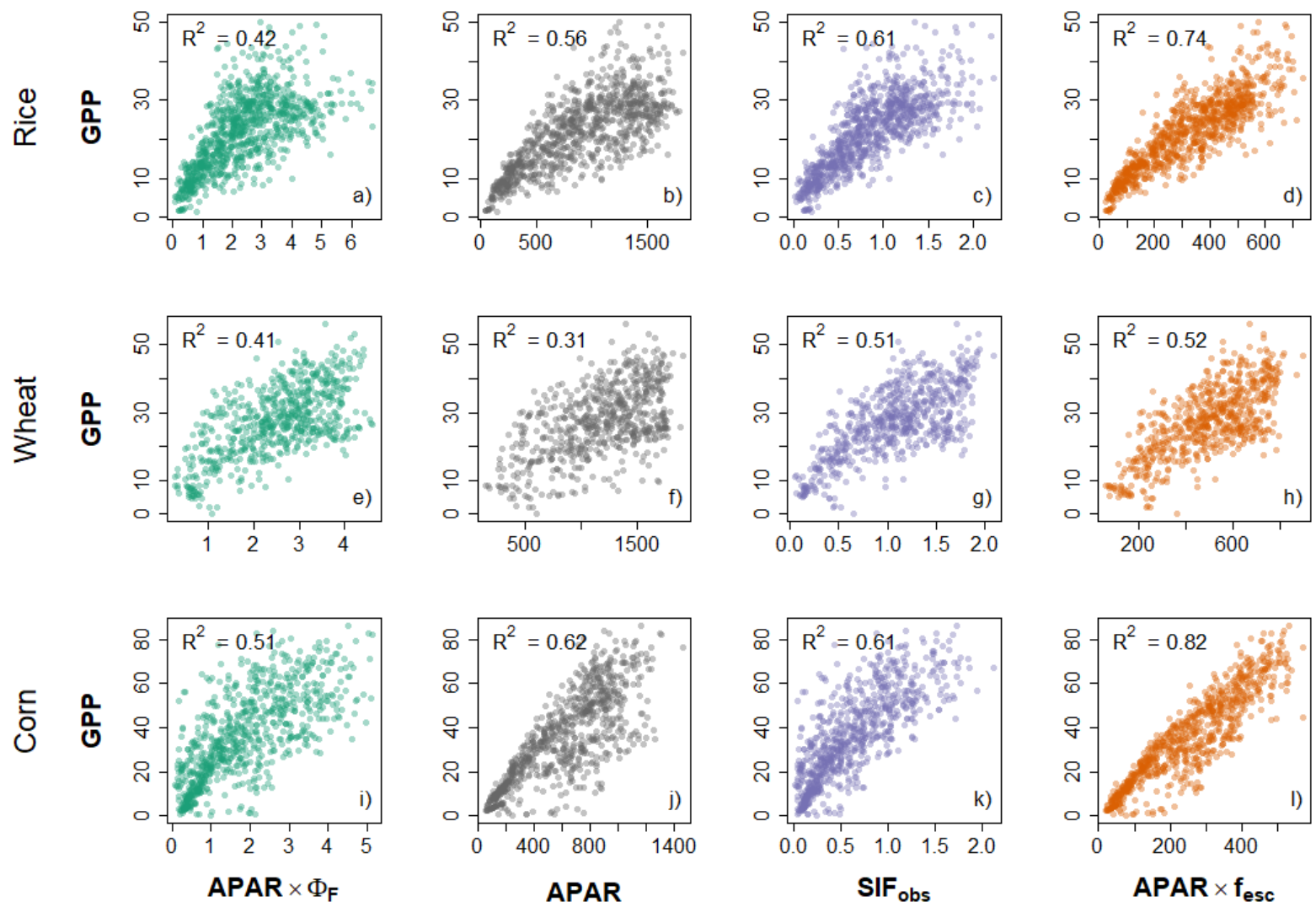

Figure 4: Overview of relationships between gross primary productivity (GPP) and SIF-related variables at half-hourly temporal resolution for the whole growing season (as far as data was available). Absorbed photosynthetically active radiation (APAR), and the two other SIF-related variables. GPP ( $\left.\mu \mathrm{mol} \mathrm{m} \mathrm{m}^{-2} \mathrm{~s}^{-1}\right)$ is compared with APAR $\left(\mu \mathrm{mol} \mathrm{m}^{-2} \mathrm{~s}^{-1}\right)$ in panels $a, e, i$, the

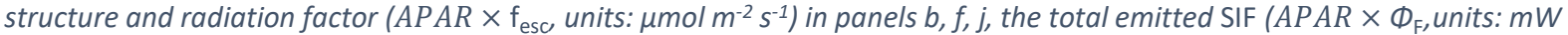
$m^{-2} m^{-1} s^{-1}$ ) in panels $c, g, k$, and with observed SIF (SIF ${ }_{o b s}$, units: $m W m^{-2} n^{-1} s^{-1}$ ) in panels $d, h$, I. Relationships are shown on the basis of half-hourly data covering one growing season for each crop. Significant squared Pearson correlation values $\left(R^{2}\right)$ are shown for reference. All data are shown as partially transparent, filled circles in order to visualize the density of points.

When considering relationships to APAR rather than GPP, both APAR $\times \mathrm{f}_{\mathrm{esc}}$ and APAR $\times \Phi_{\mathrm{F}}$ had a stronger correlation to APAR than $\mathrm{SIF}_{\mathrm{obs}}$ (Fig. $5 \mathrm{~b}$ and Fig. $\mathrm{C} 1$ in the appendix). For APAR $\times \Phi_{\mathrm{F}}$, the improvement was largest for wheat with differences in $\mathrm{R}^{2}$ reaching 0.2 , intermediate for corn and smallest for rice (Figs. 5b, S3b). For APAR $\times f_{\text {esc }}$, the improvement in relationships to APAR was on a similar level for rice and wheat and somewhat larger for corn, reaching differences in $\mathrm{R}^{2}$ of $0.2-0.3$ with the highest values for the diurnal variability (Figs. 5b, S3d). Overall and for half-hourly values, the 
relationship between $\mathrm{SIF}_{\text {obs }}$ and APAR was stronger in rice, than in corn and wheat $\left(\mathrm{R}^{2}\right.$ of $0.72,0.65$, 0.62, respectively; Fig. C1) but the differences were smaller for the seasonal variability. A more detailed analysis of the relationships between APAR and either $\mathrm{SIF}_{\mathrm{obs}}, \mathrm{APAR} \times \mathrm{f}_{\mathrm{esc}}$ or $\mathrm{APAR} \times \Phi_{\mathrm{F}}$ in terms of patterns in the half-hourly scatter plots is presented in Appendix C.

Overall, the patterns in correlations to GPP and APAR were qualitatively very similar for rice and corn, but differed for wheat (Fig. 5a,b).

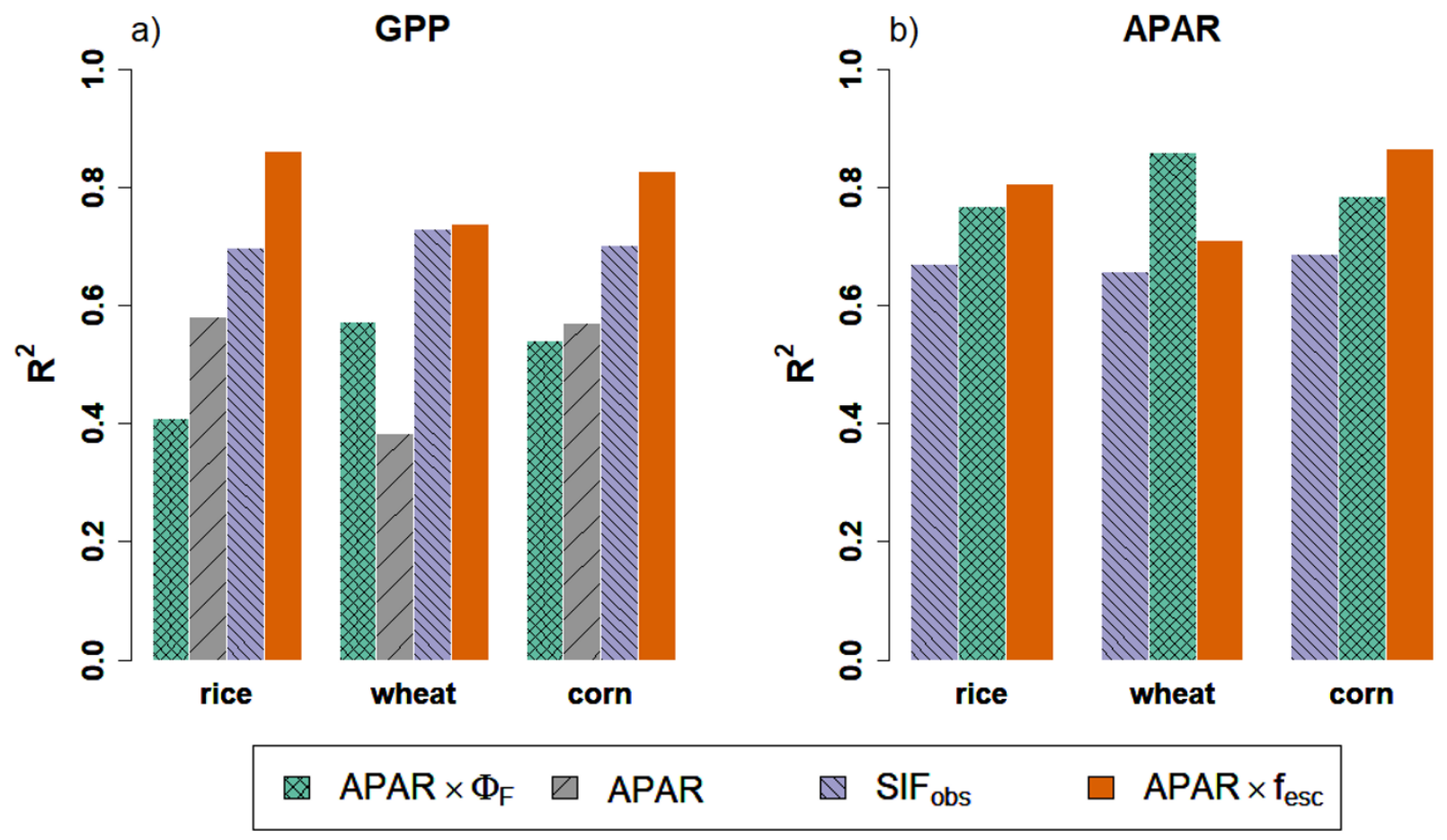

Figure 5: Overview of estimation performance of gross primary productivity (GPP) and absorbed photosynthetically active radiation (APAR) based on different SIF-related predictor variables. Results are shown for daily mean values over the whole growing season. Significant squared Pearson correlation coefficient values $\left(R^{2}\right)$ are given per crop and predictor variable.

\section{Discussion}

\subsection{Hypothesis evaluation}

In this study, we comprehensively investigated the relationships between SIF and GPP by decomposing observed SIF ( SIF $\left._{\text {obs }}\right)$ into its canopy structure and radiation component, $A P A R \times f_{\text {esc }}$, and its total emission component, $\mathrm{APAR} \times \Phi_{\mathrm{F}}$, which contains the physiological emission yield term, 
$\Phi_{\mathrm{F}}$ (Fig. 1, Table 1). This decomposition allowed us to directly examine the mechanistic basis of the SIF - GPP relationship beyond the overall dominant factor APAR by studying the underlying relationships of $f_{\text {esc }}$ and $\Phi_{F}$ to $L U E_{p}$. Relationships of of the SIF-related variables to APAR instead of GPP were also studied for comparison.

Overall, we found strong support for the hypothesis $\mathrm{H}_{\text {struc, }}$ which states that canopy structure, as captured by the escape fraction $\left(\mathrm{f}_{\mathrm{esc}}\right)$, underlies the observed $\mathrm{SIF}_{\mathrm{obs}}-\mathrm{GPP}$ relationship beyond the dominant and common driver APAR (Fig. 6). Moreover, we found that GPP estimation based on $\mathrm{APAR} \times \mathrm{f}_{\text {esc }}$ performed considerably better than or equally well as $\mathrm{SIF}_{\text {obs }}$ (see Section 4.2 for a more detailed discussion and the link to NIR ). These findings held consistently at seasonal time scales for the rice and corn datasets and to a lesser degree for the wheat dataset. Even though for wheat data $H_{\text {struc }}$ was not strictly fulfilled, the correlation of $f_{\text {esc }}$ to $L U E_{p}$ was considerably stronger than the correlation of $\Phi_{F}$ to $L U E_{P}$ (Fig. B1a,c). We did not find any results directly supporting the hypothesis $H_{\text {phys }}$, which states that $\Phi_{F}$ carries the more relevant information for LUE $E_{P}$ estimation and that $f_{\text {esc }}$ is a distorting factor. However, the results based on the diurnal variability, especially for wheat, indicated that $\mathrm{H}_{\text {struc }}$ may not hold, in the strictest sense, at the diurnal time scale. This appears to be consistent with the findings of Dechant et al. (2019) who reported larger contributions of SIF at the diurnal than the seasonal time scales for process-based simulations based on the rice paddy dataset.

The correlations to $\mathrm{LUE}_{\mathrm{p}}$ for diurnal variability showed different patterns compared to the seasonal variability for $\Phi_{\mathrm{F}}$ and $\mathrm{f}_{\mathrm{esc}}$. For $\Phi_{\mathrm{F}}$, the correlations based on diurnal variability exceeded the $R^{2}$ values that included seasonal (Fig. B1b). For $f_{e s c}$, the diurnal correlations were consistently and considerably lower than those for seasonal+diurnal variability and seasonal variability, although the differences were considerably smaller for rice than for wheat and corn (Fig. B1).

Our study made, to some degree, use of a novel framework of comparative analysis of the GPP vs. APAR estimation performance based on the three predictor variables $\operatorname{SIF}_{\mathrm{obs}}, \mathrm{APAR} \times \Phi_{\mathrm{F}}$, and APAR $\times f_{\text {esc }}$ of which a detailed version is presented in the supplementary material (Table S1, Fig. S3). The motivation for this was to ensure logical consistency of results as well as a plausibility check for a reasonable performance of our $\mathrm{f}_{\mathrm{esc}}$ estimation approach that has so far not yet been applied to measured data (Zeng et al., 2019). The necessary condition for a reasonable $f_{\text {esc }}$ estimation given a considerable seasonal variability is that dividing SIF $_{\text {obs }}$ by $f_{\text {esc }}$ estimate results in improved APAR estimation performance (Table S1). This was strictly fulfilled for all three crop types and for all variability cases including diurnal and seasonal variations (Fig. S3). Also, the results of rice and corn 
strictly fulfilled the strong form of $\mathrm{H}_{\text {struc, }}$ while the result of wheat only fulfilled a weaker form of $\mathrm{H}_{\text {struc }}$ (see Table 1).

To ensure the generality of our results for different sky conditions, we examined the influence of the diffuse PAR fraction on our results by analyzing clear sky and cloudy sky data separately (Fig. S5). These results confirmed our main finding that $\mathrm{f}_{\mathrm{esc}}$ was much more related to than $\Phi_{\mathrm{F}}$. Only for the daily mean wheat data, $\Phi_{F}$ showed a much stronger correlation to LUE for cloudy conditions than for sunny and the combined data, but this was due to a confounding effect of cloudy sky data and the senescence phase, which dominates the correlations to $L_{U E}$. More detailed analyses of the effects of the fraction of diffuse light on the SIF-GPP relationship can be found in the original publications of each dataset, i.e. K. Yang et al. (2018), Goulas et al. (2017), and Li et al. (2020).

Our analysis strongly focused on the separate results for each dataset. The motivation for this was to examine the temporal relationships as also observed in a given remote sensing pixel over time. As long as it is not covered by evergreen vegetation, each such vegetation pixel, and each of our datasets, shows considerable variation in the canopy structure parameters such as LAI, leaf angle distribution and clumping, over the growing season. Nevertheless, due to overall differences in e.g. leaf angle distribution between the crop types, differences could be expected in the results for an analysis of all data pooled together. We tested this for the case of only the two C3 crop types and all three crop types by applying a scaling factor to obtain comparable magnitudes of C3 and C4 GPP. We found consistent results compared to the separate analyses of each dataset (Fig. S7). However, when combining datasets from several ecosystems with stronger differences in canopy structure, the results could differ, as dividing by $f_{\text {esc }}$ can account for some of the structural differences. This is related to the discussion on the spatial case in section 4.5, where a more detailed reasoning is presented. 


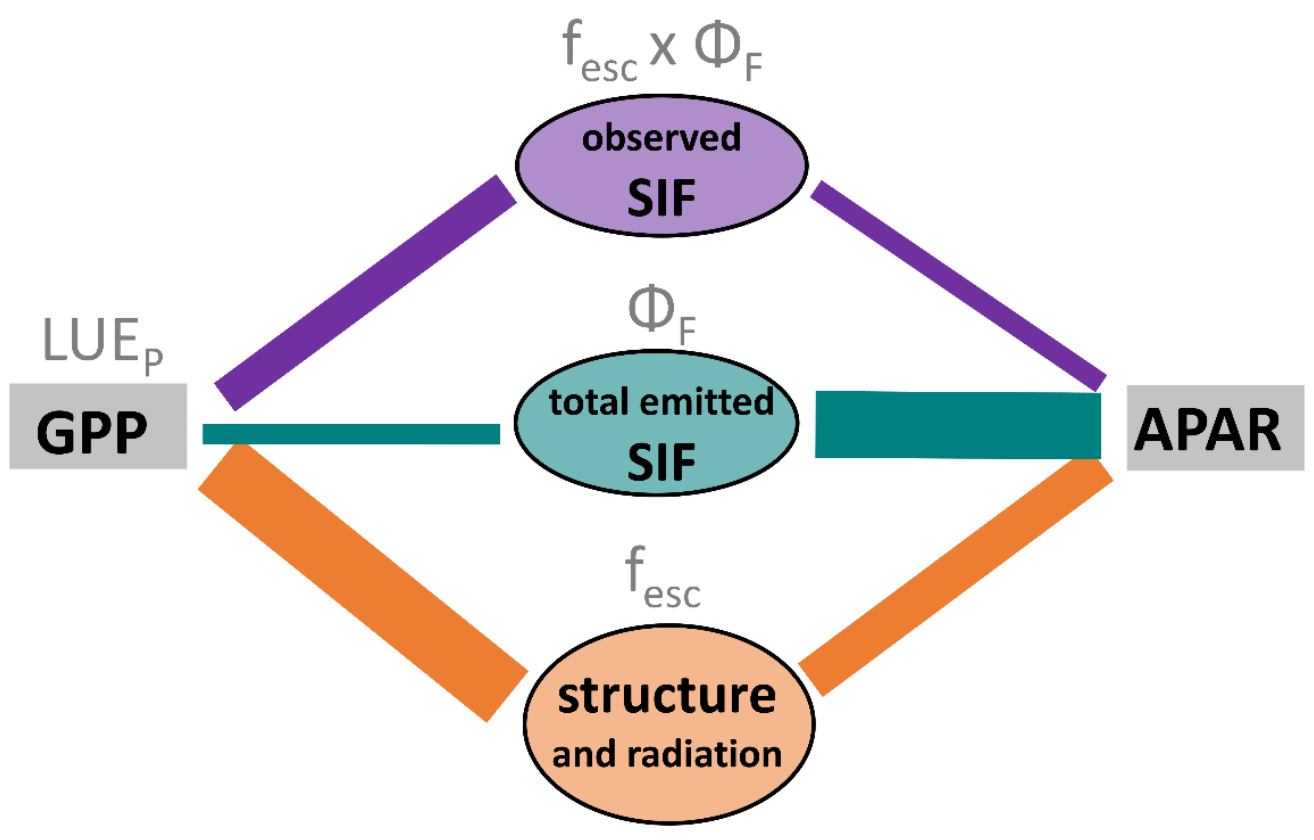

Figure 6: Schematic overview of the observed relationships between SIF-related terms and either absorbed photosynthetically

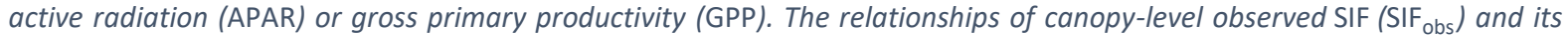
two components, total emitted SIF $\left(A P A R \times \Phi_{\mathrm{F}}=\mathrm{SIF}_{\mathrm{obs}} / \mathrm{f}_{\mathrm{esc}}\right)$ and the canopy structure and radiation factor $\left(A P A R \times \mathrm{f}_{\mathrm{esc}}\right.$ $\left.=\mathrm{SIF}_{\mathrm{obs}} / \Phi_{\mathrm{F}}\right)$, are shown. In addition to these terms that all contain APAR as main driver, also the corresponding ratio terms that are normalized for APAR are indicated in grey color on top of the flux variables. LUE $\mathrm{E}_{\mathrm{p}}$ is the photosynthetic light use efficiency, $\mathrm{LUE}_{\mathrm{F}}$ the apparent light use efficiency of $\mathrm{SIF}_{\mathrm{obs}}\left(\mathrm{LUE}_{\mathrm{F}}=\mathrm{SIF}_{\mathrm{obs}} / \mathrm{APAR}\right), \mathrm{f}_{\mathrm{esc}}$ is the escape fraction and $\Phi_{\mathrm{F}}$ is the physiological SIF yield. The line widths between flux terms represent strength of linear correlations (not to scale) based on the results of half-hourly time series at the seasonal time scale and include aspects of seasonal slope stability.

Our study was entirely limited to far-red SIF and therefore we cannot draw any direct conclusions on the analogous results for red SIF. While red SIF data was available for the wheat dataset, estimating $f_{\text {esc }}$ for red SIF is more challenging due to the strong reabsorption effects (Yang and van der Tol, 2018). Findings from process-based simulations for the rice paddy dataset did not indicate stronger performance of total emitted red SIF compared to total emitted far-red SIF (Dechant et al., 2019).

\section{$4.2 f_{e s c}, A P A R \times f_{e s c}$ and the important role of $N I R_{V}$}

We found strong evidence of the considerable seasonal dynamics in $f_{\text {esc }}$ that corresponded with seasonal variations in $\mathrm{LUE}_{\mathrm{p}}$ (Figs. 2 and 3). The strong variation of $\mathrm{f}_{\mathrm{esc}}$ is consistent with previous studies using both process-based simulations and in situ observations (Du et al., 2017; Fournier et al., 2012; Yang and van der Tol, 2018; Zeng et al., 2019) and contradicts studies assuming constant $f_{\text {esc }}$ (e.g. Guanter et al., 2014). In particular, the increase in $\mathrm{f}_{\mathrm{esc}}$ of rice and wheat in the early growing season coinciding with an increase in LAI is consistent with the simulation results of Fournier et al. 
(2012) and Yang and van der Tol (2018), as well as our own process-based simulations for the rice paddy (results not shown). The overall decreasing pattern for corn, in contrast, cannot be explained by the variation in LAl alone and is likely caused by variations in leaf angle distribution and clumping. While we do not have detailed measurements of such canopy structure parameters for corn, we observed seasonal changes in leaf angle distribution in rice (results not shown) and seasonal patterns in clumping index for rice were also reported in the literature (Fang et al., 2014). Therefore, the seasonal patterns of $\mathrm{f}_{\text {esc }}$ appear consistent with the relevant literature and satisfied the plausibility test of improved correlation of $\mathrm{SIF}_{\mathrm{obs}} / \mathrm{f}_{\text {esc }}$ to APAR for all three datasets (section 4.1). The diurnal variation of $f_{\text {esc }}$ (Fig. 2) was considerably smaller than the seasonal component and can, in general, be caused by interactions of canopy structure with changing solar zenith angle as well as by leaf movements (Goulas et al., 2017).

As fPAR was rather constant for the part of the growing season we studied, it is clear from Eqn. 3 that the variations in $\mathrm{f}_{\text {esc }}$ were dominated by variations in NIRV. The strong decrease in wheat despite constant total fPAR during senescence might be caused by an increase in the fraction of yellow leaves. This interpretation is supported by the drastic change in the red to far-red SIF ratio reported in Goulas et al. (2017), which indicates a decrease in chlorophyll content. This also implies a larger difference between green and total fPAR, which could lead to an underestimation in $\mathrm{f}_{\text {esc }}$ (section 4.4). Apart from pigment contents, changes in leaf angles might partly explain the observed pattern.

In terms of the absolute magnitude of $f_{\text {esc }}$, our results for the rice paddy seem to suffer from an overall underestimation as for hemispheric view, values above 0.5 are expected from the theory. For the wheat and corn datasets, the absolute magnitude is less straightforward to interpret due to the narrow angle viewing geometry, which creates a stronger dependence on leaf angle distribution. While there might be temporally constant biases in the overall magnitude of $f_{\text {esc }}$, this does not affect the results of our correlation analyses as they are insensitive to a global scaling factor.

We believe our study is the first one that explicitly investigated the relationships of $f_{\text {esc }}$ to canopy $\mathrm{LUE}_{\mathrm{p}}$, which makes a comparison with other literature somewhat indirect. Nevertheless, a strong link to previous studies on the $\mathrm{NIR}_{\mathrm{V}}$-GPP relationship (Badgley et al., 2019, 2017) can be established in the following way. APAR $\times f_{\text {esc }}$ is calculated as the simple product of $\mathrm{NIR}_{V}$ and PAR (Table 1). Therefore, our results can be considered an extension of the NIR $R_{V}$-GPP relationship first identified by Badgley et al. (2017) to the sub-daily scale. Indeed, we could demonstrate that the GPP estimation performance of the product of $\mathrm{NIR}_{V}$ times PAR (NIR $\mathrm{P}$ ) converges to NIR at time scales of about two weeks (Fig. 
S5). It is noteworthy that in contrast to other studies that simply multiplied $\mathrm{NIR}_{V}$ by PAR or short wave radiation without a solid mechanistic basis (e.g. Joiner et al., 2018), we found that $N_{V} P$ quite naturally emerges from Eqns. 3 and 5 as an estimate for APAR $\times f_{\text {esc }}$ (Table 2).

Apart from this way of linking our results to $\mathrm{NIR}_{\mathrm{V}}$, it is instructive to consider Eqn. 3 for reinterpreting $\mathrm{NIR}_{V}$ in terms of its mechanistic meaning. More specifically, Eqn. 3 can be rearranged to read $N I R_{V}=f P A R \times f_{\text {esc }}$, implying that $N I R_{V}$ integrates light absorption and $f_{\text {esc }}$. This is an intriguing consequence of the findings of Zeng et al. (2019) given that the relationship of NIR to GPP was originally only empirically motivated. Our results add further nuance by establishing an empirical relationship between $\mathrm{f}_{\mathrm{esc}}$ and $L U E_{\mathrm{p}}$.

Another relevant aspect of our findings is that the APAR $\times f_{e s c}-S_{\text {obs }}$ relationship was more consistent than the APAR $\times \Phi_{\mathrm{F}}-\mathrm{SIF}_{\mathrm{obs}}$ relationship (Fig. S6). This is due to the strong seasonality of $f_{\text {esc }}$ and overall seasonal stability of $\Phi_{F}$ (Fig. 2). As $f_{\text {esc }}$ is the slope in the $S_{\text {obs }}-\operatorname{APAR} \times \Phi_{F}$ relationship (assuming zero intercept), the seasonal variation of $\mathrm{f}_{\mathrm{esc}}$ translates into seasonally varying slopes in the $\mathrm{SIF}_{\text {obs }}-\mathrm{APAR} \times \Phi_{\mathrm{F}}$ relationship, similar to the the APAR $\times \mathrm{f}_{\text {esc }}-$ APAR relationship (Appendix $\mathrm{C}$ ). The $\mathrm{SIF}_{\mathrm{obs}}-\mathrm{APAR} \times \mathrm{f}_{\mathrm{esc}}$ relationship, in contrast has a seasonally stable slope. The relative invariance of $\Phi_{F}$ when compared to $f_{\text {esc }}$ found across all three datasets helps explain the basis of the globally consistent relationship between $\mathrm{SIF}_{\mathrm{obs}}$ and $\mathrm{NIR}_{\mathrm{V}}$ identified by Badgley, Field and Berry (2017) at the monthly time scale.

\section{3 $\Phi_{\mathrm{F}}$ and $\mathrm{APAR} \times \Phi_{\mathrm{F}}$}

While we found that variability of $\Phi_{F}$, measured in terms of the coefficient of variation (CV), were similar to that of $f_{\text {esc }}$ (Fig. B1), the variability of $\Phi_{F}$ did not correlate with LUE for rice and corn. In fact, for these two crops, the considerably high seasonal CV of $\Phi_{\mathrm{F}}$ appeared to be mainly caused by fluctuations around the mean value without a clear seasonal trend (Fig. S1). This was not the case for wheat, however, which showed more stable values and a clearly decreasing trend coinciding with senescence as well as a weak level of correlation (Figs. 2, 3 and S2). We think that this difference between datasets might be partly explained by the better signal quality of $\mathrm{SIF}_{\mathrm{obs}}$ in the wheat dataset, which is likely related to the much higher acquisition frequency (Table 3; see Section 4.4 for a more detailed discussion). Nevertheless, our results seem consistent with known, leaf-level patterns of small variation of $\Phi_{F}$ at diurnal (Gu et al., 2019) and seasonal time scales (Goulas et al., 2017). 
Moreover, Goulas et al. (2017) only found a weak correlation between actively measured $\Phi_{F}$ and $L U E_{P}$ at the leaf level, which is consistent with our canopy-level findings (Fig. 3).

We found consistently better APAR estimation performance of APAR $\times \Phi_{F}$ compared to $\mathrm{SIF}_{\text {obs }}$ (Figs. 5b and S3b). Liu et al. (2018) previously reported similar results based on site data and airborne images. It is with a certain irony that we conclude from our analyses that, $\operatorname{APAR} \times \Phi_{F}$, the physiological component of $\mathrm{SIF}_{\text {obs, }}$, appears to be better suited for estimating APAR as opposed to estimating GPP (Figs. 5, S3). This conclusion is in stark contrast to the widely held hopes of the SIF community to use the inherent physiological link between chlorophyll fluorescence and photosynthesis for improved GPP estimation (see, for example, Porcar-Castell et al., 2014). Although $\Phi_{F}$ and APAR $\times \Phi_{F}$ should theoretically help explain short-term variations in LUE $_{P}$ and GPP due to changes in non-photochemical quenching, such effects were not observed in the data we analyzed. Such possibilities, as well as the prospect of using APAR $\times \Phi_{F}$ as the basis for consistently estimating APAR at the global scale (e.g., Ryu et al., 2018, 2019), deserve continued attention in future research. Logically speaking, however, using APAR $\times \Phi_{F}$ for APAR estimation seems to be a somewhat circular approach as fPAR is used in the calculation of $f_{\text {esc }}$ that is needed to estimate APAR $\times \Phi_{F}$ (Table 1 ). Approaches to circumvent this circularity, e.g. iterative methods starting from existing fPAR products, would therefore be needed. Also, given available fPAR data, the approach could be used to estimate PAR from satellite data.

\subsection{Main sources of uncertainties and potential effects on our results}

We are aware that despite our efforts in data collection and analysis, there are several limitations potentially affecting our results, which are discussed below.

It is a well-known problem that the radiometric footprint of the instruments used for SIF $_{\text {obs }}$ retrieval and $\mathrm{NIR}_{\mathrm{V}}$ observations is typically much smaller than the eddy covariance footprint, even for a hemispheric viewing geometry (Marcolla and Cescatti, 2017). Therefore, the remote measurements typically do not fully capture the effects of spatial heterogeneity in canopy-level fluxes (Gamon, 2015; Marcolla and Cescatti, 2017). While crop fields tend to be more homogeneous than natural ecosystems, this factor is still expected to affect our results to some degree although it is hard to quantify.

There are differences between observations in narrow angle nadir (wheat and corn) vs. hemispheric (rice) viewing geometry that go beyond the size of the measurement footprint. In particular, these effects are related to the asymmetric angular patterns in canopy SIF emission, which 
are similar to the angular patterns in NIR reflectance (Liu and Liu, 2018). How these differences affect the relationships between SIF $_{\text {obs }}$ and GPP requires further investigation.

The retrieval of $\mathrm{SIF}_{\mathrm{obs}}$ introduces additional uncertainties (noise and bias), largely arising from the difficulty of retrieving the small SIF signal ( $1 \%$ of the absorbed light) from the much stronger background of reflected sunlight (Damm et al., 2011; Frankenberg and Berry, 2018; Meroni et al., 2009). In particular, these uncertainties quite directly propagate into uncertainties in our estimates of $\Phi_{F}$, as $\Phi_{F}$ was calculated as the 'residual' of $\mathrm{SIF}_{\text {obs }}$ and APAR $\times \mathrm{f}_{\mathrm{esc}}$, assuming that APAR $\times \mathrm{f}_{\mathrm{esc}}$ is much less affected by measurement uncertainties. The reason for this assumption is that only direct observations of RED and NIR reflectance and PAR were used to calculate APAR $\times f_{\text {esc }}$ (Table 1$)$. A similar reasoning as that for $\Phi_{\mathrm{F}}$ is valid for $\mathrm{APAR} \times \Phi_{\mathrm{F}}$ as the latter is the product of $\Phi_{\mathrm{F}}$ times APAR.

Apart from different choices of $\mathrm{SIF}_{\text {obs }}$ retrieval algorithms in interaction with the spectral and radiometric characteristics of the instruments and processing (Table 3, Section 2.2), differences in uncertainty in $\mathrm{SIF}_{\text {obs }}$ between datasets also arises from considerable differences in the number of spectra collected per minute. In particular, the wheat site typically collected about 60-120 times the number of spectra measured at the rice and corn sites (Table 3). Such a high acquisition frequency translates into stronger noise reduction in SIF retrievals via temporal averaging.

We think the uncertainties related to SIF retrieval do not affect our main conclusions in their essence. First, the strong evidence for $\mathrm{H}_{\text {struc }}$ is not affected by this aspect at all, as APAR $\times \mathrm{f}_{\text {esc }}$ and $f_{\text {esc }}$ are not based on $\mathrm{SIF}_{\text {obs }}$ retrievals but on $\mathrm{NIR}_{\mathrm{V}}$ (Table 1). Second, although the lack of evidence supporting $\mathrm{H}_{\text {phys }}$ appears to be partly caused by noise issues, even the wheat dataset, which apparently had the best SIF $_{\text {obs }}$ quality, did not show indications of better performance of physiological over structural information.

It is also worth noting that we used field observations of $\mathrm{fPAR}_{\text {tot }}$ rather than $\mathrm{PPAR}_{\text {green }}$ that only captures the light absorbed by chlorophyll. Previous studies have suggested to use the fraction of green LAI to total LAI to estimate fPAR green $_{\text {from }}$ PAR $_{\text {tot }}$ (Gitelson et al., 2018; Gitelson and Gamon, 2015). Such data were only available for the rice dataset, however, preventing a consistent application of the fPAR green approach to all datasets. Nevertheless, we think that using in situ measured fPAR has advantages over using an indirect estimate based on canopy reflectance due to the uncertainties in the latter approach. Using $\mathrm{PAAR}_{\text {tot }}$ rather than $\mathrm{FAR}_{\text {green }}$ is expected have an impact mainly during the senescence phase at the end of the growing season and logically should affect the estimates of $f_{\text {esc }}$, $\mathrm{LUE}_{\mathrm{P}}$, and $\mathrm{APAR} \times \Phi_{\mathrm{F}}($ Table 1). However, our interpretation of the results in terms of the strong 
performance of APAR $\times f_{\text {esc }}$ for GPP estimation is not affected as APAR $\times f_{\text {esc }}$ was estimated as NIRV $x$ PAR.

\subsection{Implications for large scale GPP estimation}

Ultimately, the main motivation to study SIF-GPP relationships is to improve the remote and largescale estimation of GPP (Ryu et al., 2019). We found that the structural component of SIF (APAR $\times$ $\mathrm{f}_{\text {esc }}$ ) showed strong linear relationships to GPP that were as good as or even better than those based on $\mathrm{SIF}_{\mathrm{obs}}$ However, our results strongly focused on crops, the site level and temporal variations.

Large scale applications using airborne or satellite SIF retrievals, however, tend to capture variations across space more than variations in time. Even when longer time series of SIF are considered, the number of pixels across space is typically much larger than the number of observation time steps. Therefore, we need to be cautious in making incorrect generalizations from the temporal case to the spatial case. Two different spatial cases should be distinguished. First, spatial variability within a given ecosystem type. This case is relevant for airborne remote sensing and could be tested in an approach that combines hyperspectral reflectance - based estimation of leaf and canopy parameters, SIF retrieval, and process-based modelling of GPP and APAR (Tagliabue et al., 2019). Second, spatial variability within and between ecosystems, which is relevant for global-scale satellite applications. In particular, several global scale studies have shown differences in the slope of SIF $_{\text {obs }}{ }^{-}$ GPP relationships between ecosystems (Guanter et al., 2014; Sun et al., 2018; Yongguang Zhang et al., 2016). Since the main origin of the slope differences for a given photosynthetic pathway is strongly suspected to be $f_{\text {esc }}$ (Zeng et al., 2019), APAR $\times f_{\text {esc }}$ should show essentially the same tendencies as $\mathrm{SIF}_{\text {obs }}$. Therefore, using $\mathrm{f}_{\text {esc }}$ to normalize the differences in slope between $\mathrm{SIF}_{\text {obs }}$ and GPP in different ecosystems, is expected to improve spatial SIF-GPP relationships. Judging from our results, however, the improvement in spatial patterns goes together with a degradation of temporal relationships. In contrast to our site-level findings, Qiu et al. (2019) reported consistent and partly considerable improvements in the temporal SIF-GPP relationships when normalizing for $f_{\text {esc }}$ based on global process-based simulations. However, small to moderate improvements and partly even degradation of results were found when applying the $\mathrm{f}_{\text {esc }}$ normalization to OCO-2 SIF retrievals and evaluating the temporal correlation to FLUXCOM GPP (Qiu et al., 2019).

For APAR $\times \mathrm{f}_{\text {esc }}$, the approach of using $\mathrm{f}_{\text {esc }}$ to correct for slope differences between SIF $_{\text {obs }}$ and GPP is 1) not possible as NIR is already used to calculate APAR $\times f_{\text {esc }}$ and 2) not desirable as $f_{\text {esc }}$ contains the LUE $_{\mathrm{P}}$-relevant information in addition to APAR. It seems, therefore, that for APAR $\times \mathrm{f}_{\text {esc }}{ }^{-}$ 
based GPP estimation, an ecosystem-dependent slope has to be applied as was partly done in Badgley et al. (2019). This is particularly relevant for evergreen needleleaf forests (ENF) that have a much lower NIR reflectance despite rather high GPP during the growing period, as can be inferred also from previous studies investigating SIF $_{\text {obs }}$-GPP relationships (Sun et al., 2018; Yao Zhang et al., 2018a). Based on our results, different slopes need to be applied for C3 and C4 species no matter if $\mathrm{SIF}_{\text {obs }}$ or APAR $\times f_{\text {esc }}$ is used (Fig. S12), which indicates that ecosystem- or pathway-dependent slopes will be required to some degree for global studies in any case. Further research is needed to determine if $\mathrm{SIF}_{\text {obs }}$ considerably outperforms APAR $\times \mathrm{f}_{\text {esc }}$ for GPP estimation in ENF ecosystems where canopy structure is stable but photosynthesis and $\Phi_{\mathrm{F}}$ are downregulated in winter (Magney et al., 2019; Porcar-Castell, 2011; Raczka et al., 2019).

A point of practical interest is that the product of NDVI times the upwelling NIR radiance $\left(N I R_{V} R\right)$ shows very strong correlation to $\mathrm{NIR}_{\mathrm{V}} \mathrm{P}$ (Fig. D1 in the appendix) and is therefore an alternative that only needs data from the RED and NIR bands. The results of NIR $R$ and NIR $P$ showed similar levels of performance for GPP estimation (Fig. D2). As NIR $R$ does not require separate PAR data, it might have advantages over NIR $_{V} P$ for satellite-based applications at large scales where PAR data are not readily available despite recent progress (Ryu et al., 2018).

Apart from the different impacts of temporal and spatial variation, there is another aspect to consider for satellite applications. In contrast to ground-based observations, non-geostationary satellites take snapshots at a given moment in time, not daily mean values. While the expected effects of this were previously simulated and directly examined in several studies (Yongguang Zhang et al., 2016; Yao Zhang et al., 2018b), we found overall consistent patterns compared to using half-hourly values with only minor differences in terms of the performance ranking (Fig. S8). We therefore conclude that our findings are particularly relevant for satellite-based applications when considering the temporal (per-pixel) variability. Future SIF retrievals from geostationary missions such as TEMPO (Zoogman et al., 2017) or GeoCarb (Moore III et al., 2018) could provide the basis for large scale analyses similar to our site-level approach.

\section{Conclusion}

We mechanistically decomposed canopy-level SIF $_{\text {obs }} /$ APAR at three crop sites into the physiological emission yield, $\Phi_{F}$, and the canopy escape fraction, $f_{\text {esc }}$, and examined their relationships to the photosynthetic light use efficiency, LUE . We found that $\mathrm{f}_{\text {esc }}$ had a considerable seasonal correlation 
to $L_{\mathrm{E}}$ across the three sites, while $\Phi_{\mathrm{F}}$ was essentially uncorrelated and did not show any clear seasonal patterns. Even at the diurnal scale, $\Phi_{F}$ did not outperform $f_{\text {esc }}$ in terms of correlation to LUE $_{P}$ except in the case of the wheat site. Consistent with these results, we found that the canopy structure and radiation component of SIF, APAR $\times f_{\text {esc }}$, was a better estimator of GPP than the total emission component of SIF, APAR $\times \Phi_{F}$. In fact, APAR $\times f_{\text {esc }}$ even outperformed SIF ${ }_{\text {obs }}$ for GPP estimation for two of the three sites and had comparable performance to $\mathrm{SIF}_{\mathrm{obs}}$ for the remaining crop. APAR $\times \Phi_{\mathrm{F}}$, in contrast, improved the relationship to APAR compared to $\mathrm{SIF}_{\mathrm{obs}}$, but had a considerably weaker performance for GPP estimation than $\mathrm{SIF}_{\text {obs }}$. Importantly, the canopy structure and radiation component of SIF can be observed on the basis of the near-infrared reflectance of vegetation NIRV with multispectral instruments without the need for SIF retrieval or explicit fPAR or even PAR information. Without independent PAR observations, the upwelling near-infrared radiance of vegetation can be used directly as estimate of APAR $\times \mathrm{f}_{\text {esc }}$.

Our findings focus on the temporal relationships at the seasonal time scale and highlight the importance of the canopy structure effects on the SIF $_{\text {obs }}$ signal, as well as APAR $\times \mathrm{f}_{\text {esc }}$ as effective GPP proxy in crops. Apart from providing further evidence of the practical usefulness of $N_{I} R_{V}$ in general and the $\mathrm{NIR}_{\mathrm{V}}$-based escape fraction formula in particular, we presented a comprehensive framework of analyzing the separate contributions of $\Phi_{F}$ and $f_{\text {esc }}$ that is expected to stimulate future research. 


\section{Acknowledgements}

Many people contributed to the collection and processing of the in situ data sets and we are grateful for their contributions. We thank Kaige Yang, Hyungsuk Kimm and Jongmin Kim from Seoul National University (SNU) for contributing to field measurements and SIF retrieval processing for the rice paddy data set. We also thank Ari Kornfeld from the Carnegie Institution for Science and Xi Yang from the University of Virginia for helping to set-up and run the spectrometer systems in the rice paddy and providing support in the data processing and troubleshooting. We thank Olivier Marloie for processing eddy covariance flux data for the wheat field and are grateful for the contributions of the team at Ecole Polytechnique to the development of the TriFLEX instrument that was used for the data collection. We also thank Shihua Zhu from Nanjing University as well as Hezhou Wang, Pengju Wu and other researchers from the ShangQiu station of the Farmland Irrigation Research Institute of the Chinese Academy of Agricultural Sciences for their support with field measurements for the corn data set. This research was funded by the National Research Foundation of Korea (NRF2016M1A3A3A02018195). The SIF joint workshop between SNU and Nanjing University funded by the National Research Foundation of Korea (NRF-2018K2A9A2A05018142) contributed to this manuscript. Processing of the wheat data was funded by the Centre National d'Etudes Spatiales, Terre Océan Surfaces Continentales Atmosphère (CNES TOSCA) program. English proofread service was supported by Research Institute of Agriculture and Life Sciences in SNU. We thank three anonymous reviewers for their comments that helped to improve the manuscript. 
Appendix A. Temporal patterns of APAR, GPP, SIF obs, $_{\text {APAR }} \times \mathrm{f}_{\mathrm{esc}}$, and $\operatorname{APAR} \times \Phi_{\mathrm{F}}$

Rice
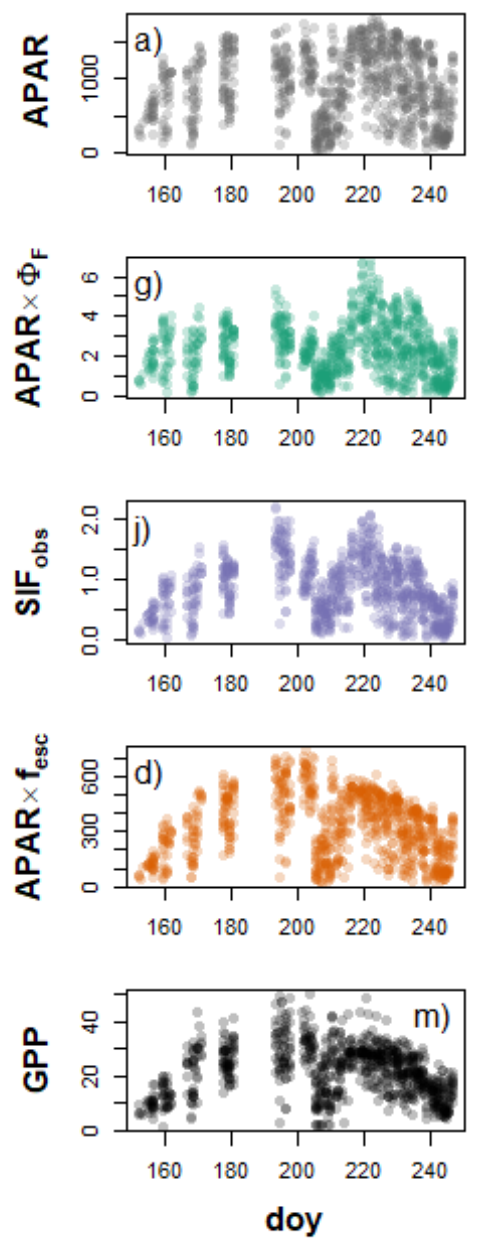

Wheat
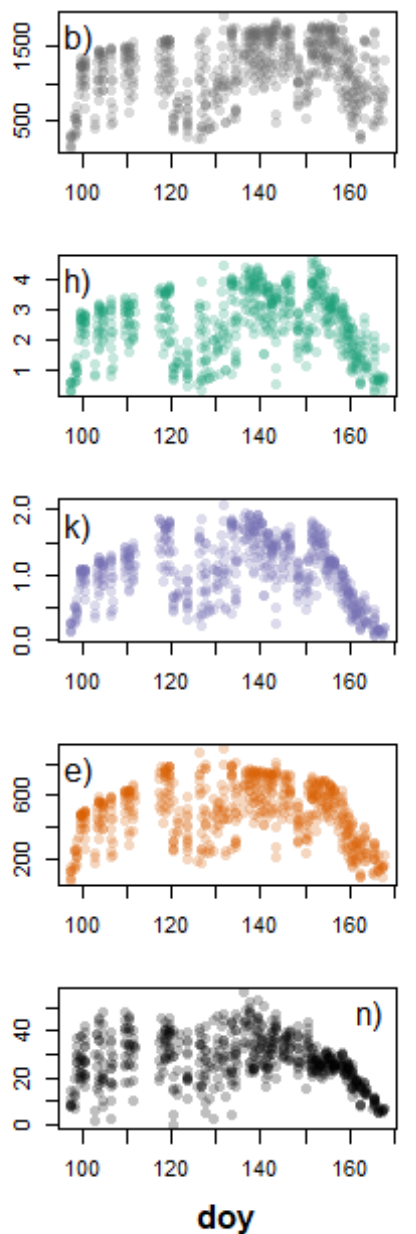

Corn
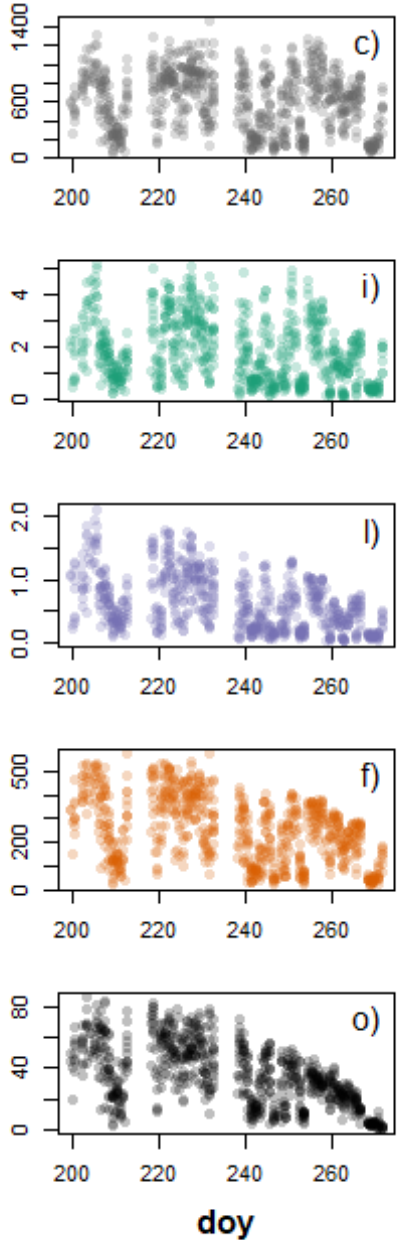

Figure A1: Overview of the temporal patterns of the main variables related to GPP. Half-hourly data for the same data selection as in Fig. 4 are shown. Note that the y-axis scales are not the same for the different crop types in order to facilitate the visual comparison of temporal patterns. Units are as in Fig. 4. 
Appendix B. Relationships to $L E_{p}$ at different time scales

$\mathrm{LUE}_{\mathrm{F}}$

b)

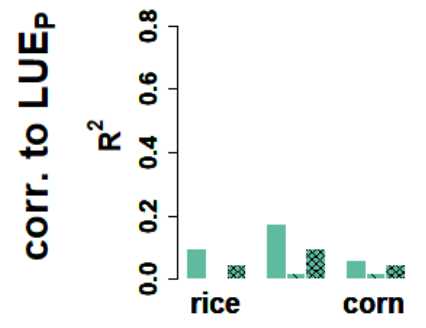

d)

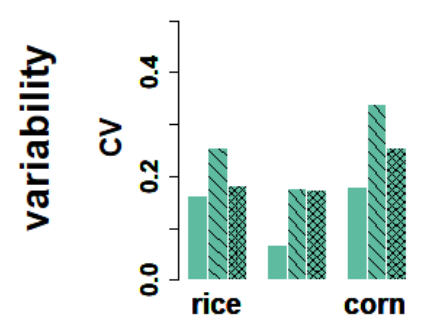

LUE $_{\mathrm{F}}$

a)

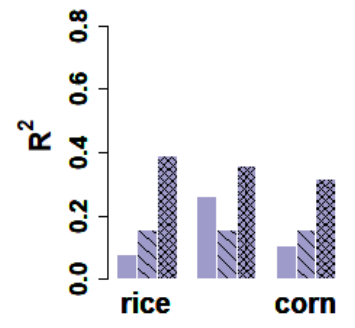

e)

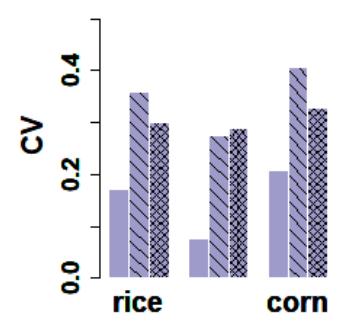

c)

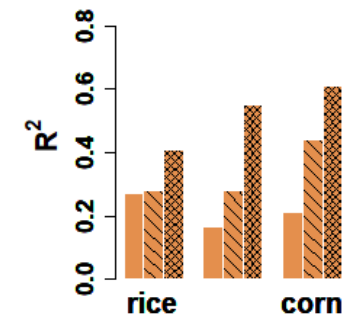

f)

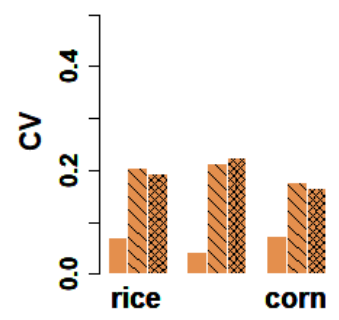

LUE $_{\mathrm{P}}$

$\square$ diurnal

$\square$ seas.+diurn.

g)

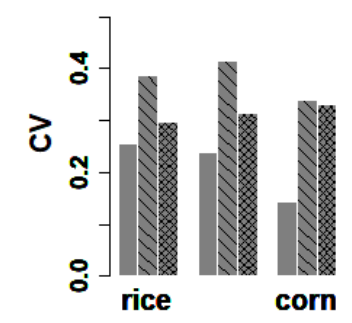

Figure B1: Overview of $(a-c)$ correlation to LUEP and $(d-g)$ coefficient of variation $(C V)$. $L U E_{F}=f_{\text {esc }} \times \Phi_{F}$. The results correspond to Fig. 3 in the main text. 


\section{Appendix C. Relationships between APAR and SIF}

As in Fig. 4 only the $R^{2}$ results for the relationships between $\operatorname{SIF}_{\text {obs }}, A P A R \times f_{\text {esc }}$ and APAR $\times \Phi_{F}$ and GPP are shown, we include the detailed relationships between APAR on the one hand and SIF $_{\text {obs, }}$, APAR $\times f_{\text {esc }}$ and APAR $\times \Phi_{F}$ on the other hand here (Fig. C1).
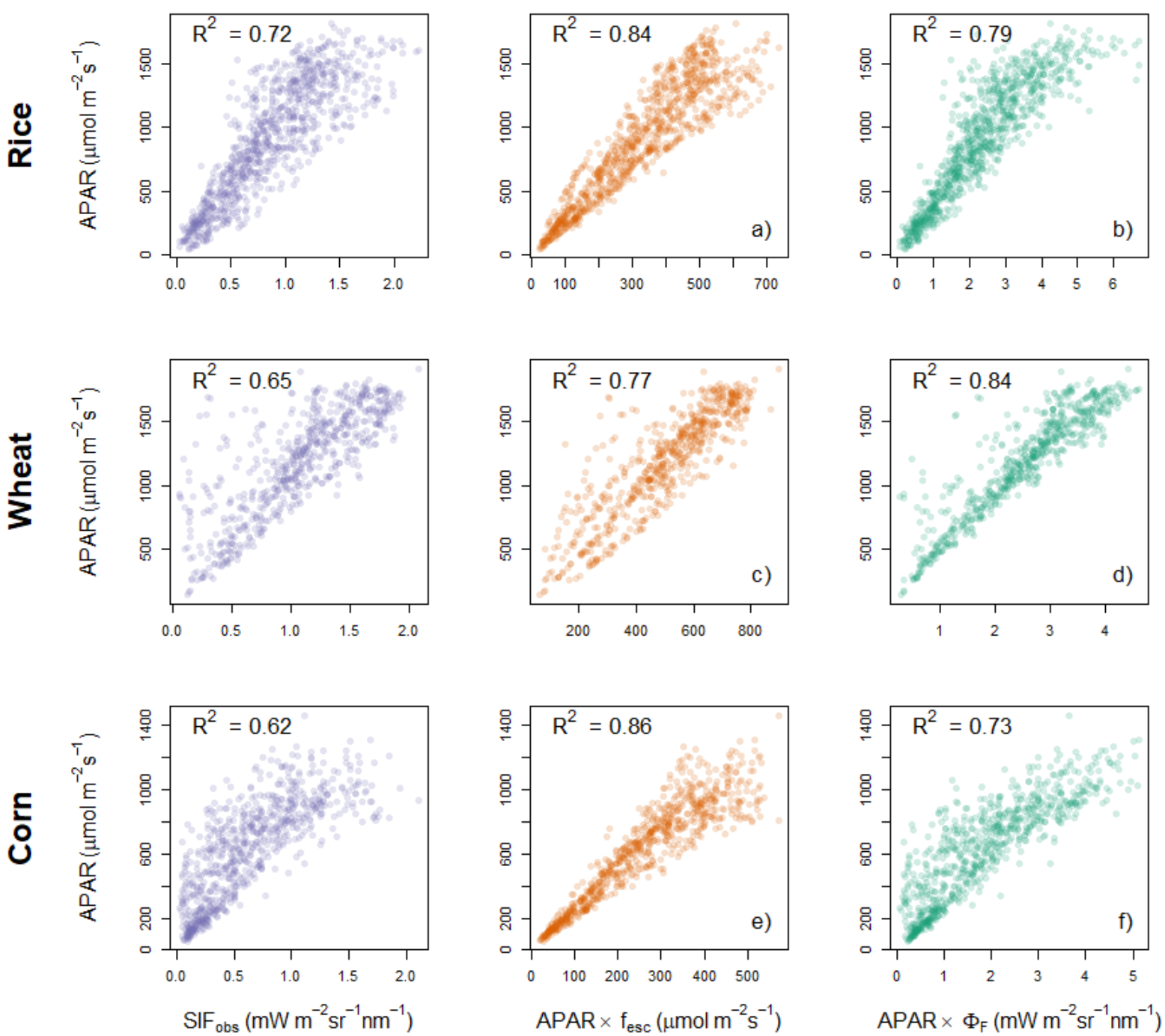

Figure C1: Illustration of the effect of seasonal changes in $\mathrm{f}_{\mathrm{esc}}$ on the relationship between APAR $\times \mathrm{f}_{\mathrm{esc}}$ and APAR for the wheat dataset. As $\mathrm{f}_{\mathrm{esc}}$ is the ratio of APAR $\times \mathrm{f}_{\mathrm{esc}}$ and APAR, its seasonal changes (panel c) directly correspond to seasonal changes of the slope in the relationship.

It is instructive to study the patterns in the scatterplots in Fig. C1, as there are partly relatively small differences in $\mathrm{R}^{2}$ between APAR $\times \Phi_{\mathrm{F}}$ and APAR $\times \mathrm{f}_{\mathrm{esc}}$ but clear patterns of seasonally varying slopes 
in the APAR $\times \mathrm{f}_{\text {esc }}$-APAR relationships. This can be well illustrated with the example of the wheat dataset (Fig. C2). Assuming a zero intercept, the slope in the APAR $\times \mathrm{f}_{\mathrm{esc}}-\mathrm{APAR}$ relationship is simply the ratio of APAR /(APAR $\left.\times f_{\text {esc }}\right)$, which is $1 / f_{\text {esc }}$. As $f_{\text {esc }}$ is showing considerable seasonal variation, this is reflected also in the slope. An illustration of this situation is shown in Fig. C2. The reason why the APAR $\times \Phi_{\mathrm{F}}$-APAR relationship does not show such varying slope patterns is that $\Phi_{\mathrm{F}}$ did not show clear seasonal trends (Fig. 2od-f).
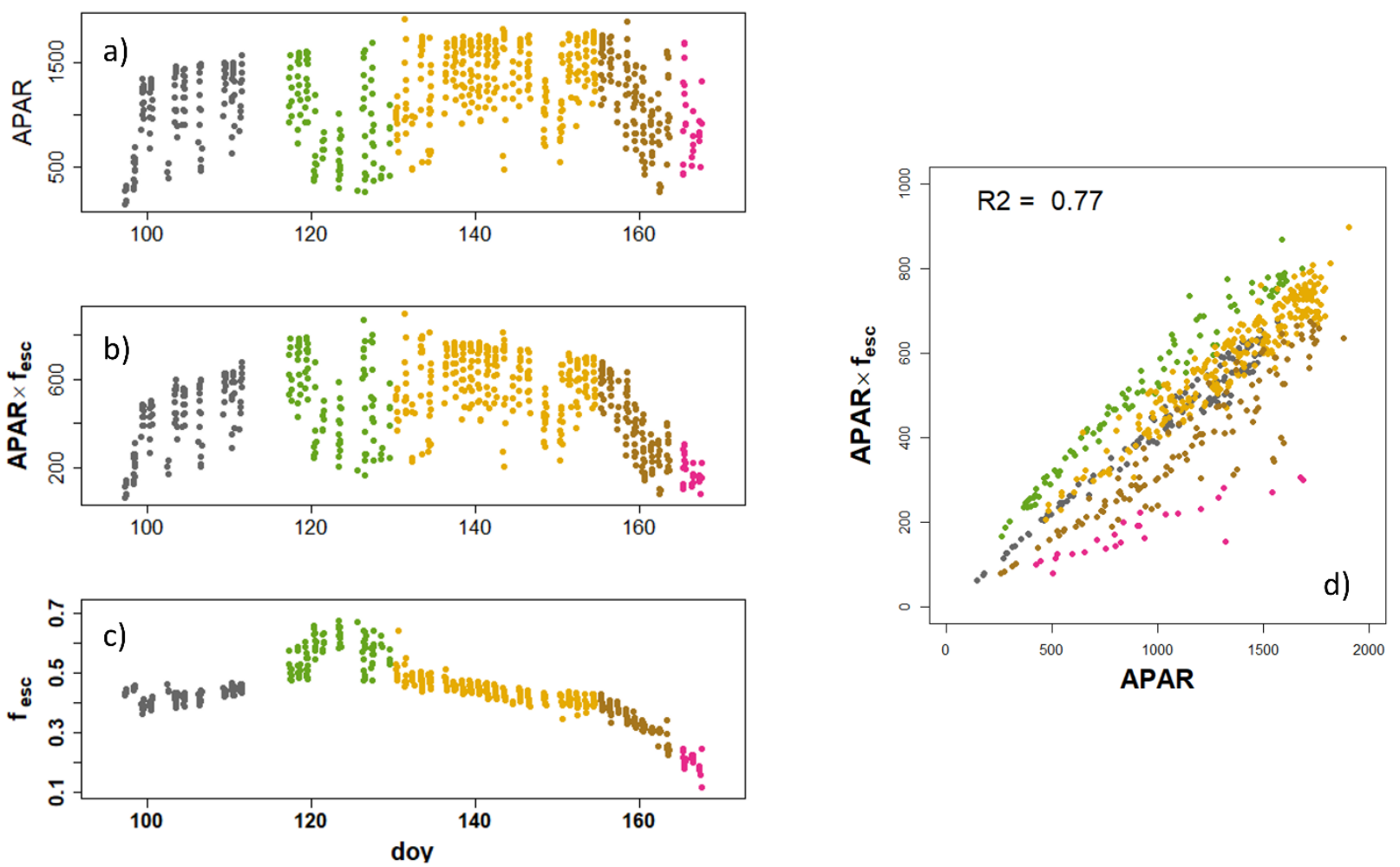

Figure C2: Illustration of the effect of seasonal changes in $\mathrm{f}_{\mathrm{esc}}$ ) on the relationship between APAR $\times \mathrm{f}_{\mathrm{esc}}$ and APAR for the wheat dataset. As $\mathrm{f}_{\mathrm{esc}}$ is the ratio of APAR $\times \mathrm{f}_{\mathrm{esc}}$ and APAR, its seasonal changes (panel c) directly correspond to seasonal changes of the slope in the relationship (panel d). 


\section{Appendix D. Comparison of $N I R_{V} R$ and $N_{I} R_{V} P$ for practical purposes}

$N I R_{V} P=N I R_{V} \times P A R$ requires PAR information that cannot be obtained directly from multispectral sensors designed for $\mathrm{NDVI}$ and $\mathrm{NIR}_{\mathrm{V}}$ observations. Although eddy covariance towers are typically equipped with separate quantum sensors for PAR measurements, some sites without eddy covariance instruments might not have such sensors. Therefore, using the radiance version $N I R_{V} R=N I R_{V} \times($ downwelling nir Radiance) $=N D V I \times($ upwelling nir radiance) could be useful in certain circumstances ("nir" was used to denote "near-infrared" here, as "NIR" was defined as nir reflectance, see Table 2). For example, when using airborne or satellite observations, the radiance data from the sensors in the atmospheric window around the $\mathrm{O}_{2} \mathrm{~A}$ band does not require atmospheric correction and therefore has a clear practical advantage (Köhler et al., 2018; Zeng et al., 2019). For all three crop datasets, we found very strong correlations of $N R_{V} R$ and $N I R_{V} P$ when using the full half-hourly time series (Fig. D1). The reason underlying the strong $N I R_{V} R$ and $N I R_{V} P$ correlations is the strong correlation of incoming PAR and downwelling near-infrared irradiance. While it is known from atmospheric radiative transfer theory that the relationship between the downwelling near-infrared radiance and incoming PAR is affected by the diffuse fraction of PAR, this effects seems negligible at the seasonal time scale.
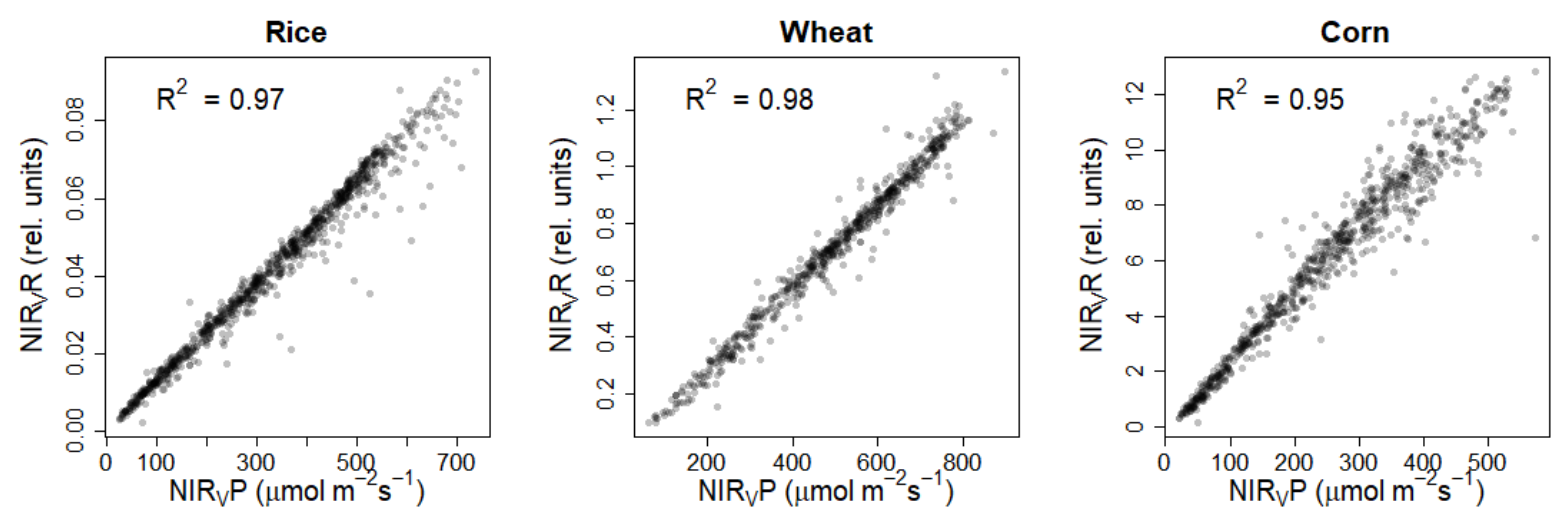

Figure D1: Comparison of $\mathrm{NIR}_{\mathrm{V}} P=\mathrm{NIR}_{\mathrm{V}}$. PAR with the radiance based version $\mathrm{NIR}_{\mathrm{V}} R=N D V I \cdot$ (near-infrared upwelling radiance) for the three crop datasets (half-hourly values, seasonal time scale). $N I R_{V} P$ and $N I R_{V} R$ are shown in relative units.

As can be expected from the very high linear correlation shown in Fig. $D 1, N I R_{V} R$ and $N I R_{V} P$ have essentially the same performance for GPP estimation (Fig. D2). 
$\mathbf{N I R} \mathbf{R}_{\mathrm{V}} \mathbf{R}=\mathbf{N I R _ { \mathrm { V } }} \times$ downw. nir Rad.

$N_{1} P=N I R_{V} \times P A R$
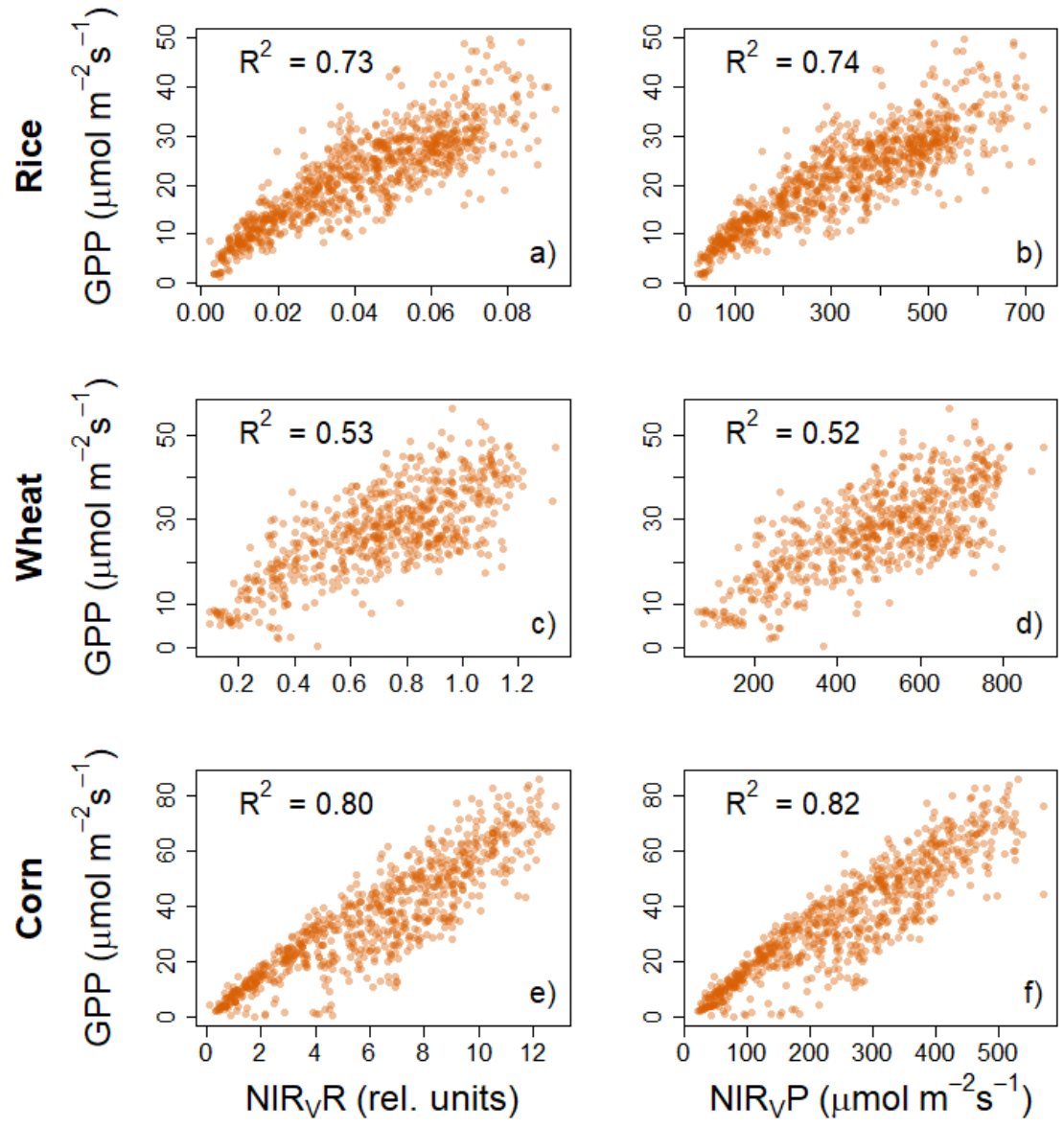

Figure D2: Relationships of a), c), e) $\mathrm{NIR}_{\mathrm{V}} R$ to GPP compared to b),d),f) NIR $\mathrm{P}$ to GPP for the three crop datasets. Panels b),d),f) are identical to Fig. $4 d, h$,i) except for the $x$-axis label and are only shown here for easier direct comparability of results. The definitions of $\mathrm{NIR}_{\mathrm{V}} R$ and $\mathrm{NIR} R$ is given on the top of each panel column, "downw. nir Rad." Stands for downwelling nearinfrared radiance.

\section{Appendix E. Supplementary data}

Supplementary data to this article can be found online at [insert DOI link] 


\section{References}

Badgley, G., Anderegg, L.D.L., Berry, J.A., Field, C.B., 2019. Terrestrial Gross Primary Production: Using NIRv to Scale from Site to Globe. Global Change Biology. https://doi.org/10.1111/gcb.14729

Badgley, G., Field, C.B., Berry, J.A., 2017. Canopy near-infrared reflectance and terrestrial photosynthesis. Science Advances 3, e1602244.

Borchers, H.W., 2018. pracma: Practical Numerical Math Functions. R package version 2.2.2. https://CRAN.R-project.org/package=pracma

Damm, A., Erler, A., Hillen, W., Meroni, M., Schaepman, M.E., Verhoef, W., Rascher, U., 2011. Modeling the impact of spectral sensor configurations on the FLD retrieval accuracy of sun-induced chlorophyll fluorescence. Remote Sensing of Environment 115, 1882-1892. https://doi.org/10.1016/j.rse.2011.03.011

Daumard, F., Champagne, S., Fournier, A., Goulas, Y., Ounis, A., Hanocq, J.-F., Moya, I., 2010. A Field Platform for Continuous Measurement of Canopy Fluorescence. IEEE Transactions on Geoscience and Remote Sensing 48, 3358-3368. https://doi.org/10.1109/TGRS.2010.2046420

Dechant, B., Ryu, Y., Kang, M., 2019. Making full use of hyperspectral data for gross primary productivity estimation with multivariate regression: Mechanistic insights from observations and processbased simulations. Remote Sensing of Environment 234, 111435. https://doi.org/10.1016/j.rse.2019.111435

Devore, J.L., 2011. Probability and Statistics for Engineering and the Sciences. Cengage learning.

Dolman, A.J., Noilhan, J., Durand, P., Sarrat, C., Brut, A., Piguet, B., Butet, A., Jarosz, N., Brunet, Y., Loustau, D., Lamaud, E., Tolk, L., Ronda, R., Miglietta, F., Gioli, B., Magliulo, V., Esposito, M., Gerbig, C., Körner, S., Glademard, P., Ramonet, M., Ciais, P., Neininger, B., Hutjes, R.W.A., Elbers, J.A., Macatangay, R., Schrems, O., Pérez-Landa, G., Sanz, M.J., Scholz, Y., Facon, G., Ceschia, E., Beziat, P., 2006. The CarboEurope Regional Experiment Strategy. Bulletin of the American Meteorological Society 87, 1367-1380. https://doi.org/10.1175/BAMS-87-10-1367

Du, S., Liu, L., Liu, X., Hu, J., 2017. Response of Canopy Solar-Induced Chlorophyll Fluorescence to the Absorbed Photosynthetically Active Radiation Absorbed by Chlorophyll. Remote Sensing 9, 911. https://doi.org/10.3390/rs9090911

Fang, H., Li, W., Wei, S., Jiang, C., 2014. Seasonal variation of leaf area index (LAI) over paddy rice fields in NE China: Intercomparison of destructive sampling, LAI-2200, digital hemispherical photography (DHP), and AccuPAR methods. Agricultural and Forest Meteorology 198-199, 126-141. https://doi.org/10.1016/j.agrformet.2014.08.005

Fournier, A., Daumard, F., Champagne, S., Ounis, A., Goulas, Y., Moya, I., 2012. Effect of canopy structure on sun-induced chlorophyll fluorescence. ISPRS Journal of Photogrammetry and Remote Sensing 68, 112-120. https://doi.org/10.1016/j.isprsjprs.2012.01.003

Frankenberg, C., Berry, J., 2018. Solar Induced Chlorophyll Fluorescence: Origins, Relation to Photosynthesis and Retrieval, in: Comprehensive Remote Sensing. Elsevier, pp. 143-162. https://doi.org/10.1016/B978-0-12-409548-9.10632-3

Frankenberg, C., Fisher, J.B., Worden, J., Badgley, G., Saatchi, S.S., Lee, J.-E., Toon, G.C., Butz, A., Jung, M., Kuze, A., Yokota, T., 2011. New global observations of the terrestrial carbon cycle from GOSAT: Patterns of plant fluorescence with gross primary productivity: CHLOROPHYLL FLUORESCENCE FROM SPACE. Geophysical Research Letters 38, n/a-n/a. https://doi.org/10.1029/2011GL048738

Gamon, J.A., 2015. Reviews and Syntheses: optical sampling of the flux tower footprint. Biogeosciences 12, 4509-4523. https://doi.org/10.5194/bg-12-4509-2015 
Gitelson, A.A., Arkebauer, T.J., Suyker, A.E., 2018. Convergence of daily light use efficiency in irrigated and rainfed C3 and C4 crops. Remote Sensing of Environment 217, 30-37. https://doi.org/10.1016/j.rse.2018.08.007

Gitelson, A.A., Gamon, J.A., 2015. The need for a common basis for defining light-use efficiency: Implications for productivity estimation. Remote Sensing of Environment 156, 196-201. https://doi.org/10.1016/j.rse.2014.09.017

Goulas, Y., Fournier, A., Daumard, F., Champagne, S., Ounis, A., Marloie, O., Moya, I., 2017. Gross Primary Production of a Wheat Canopy Relates Stronger to Far Red Than to Red Solar-Induced Chlorophyll Fluorescence. Remote Sensing 9, 97. https://doi.org/10.3390/rs9010097

Gu, L., Han, J., Wood, J.D., Chang, C.Y., Sun, Y., 2019. Sun-induced Chl fluorescence and its importance for biophysical modeling of photosynthesis based on light reactions. New Phytologist. https://doi.org/10.1111/nph.15796

Guanter, L., Frankenberg, C., Dudhia, A., Lewis, P.E., Gómez-Dans, J., Kuze, A., Suto, H., Grainger, R.G., 2012. Retrieval and global assessment of terrestrial chlorophyll fluorescence from GOSAT space measurements. Remote Sensing of Environment 121, 236-251. https://doi.org/10.1016/j.rse.2012.02.006

Guanter, L., Rossini, M., Colombo, R., Meroni, M., Frankenberg, C., Lee, J.-E., Joiner, J., 2013. Using field spectroscopy to assess the potential of statistical approaches for the retrieval of sun-induced chlorophyll fluorescence from ground and space. Remote Sensing of Environment 133, 52-61. https://doi.org/10.1016/j.rse.2013.01.017

Guanter, L., Zhang, Y., Jung, M., Joiner, J., Voigt, M., Berry, J.A., Frankenberg, C., Huete, A.R., Zarco-Tejada, P., Lee, J.-E., Moran, M.S., Ponce-Campos, G., Beer, C., Camps-Valls, G., Buchmann, N., Gianelle, D., Klumpp, K., Cescatti, A., Baker, J.M., Griffis, T.J., 2014. Global and time-resolved monitoring of crop photosynthesis with chlorophyll fluorescence. Proceedings of the National Academy of Sciences 111, E1327-E1333. https://doi.org/10.1073/pnas.1320008111

Hampel, F.R., 1974. The influence curve and its role in robust estimation. Journal of the american statistical association 69, 383-393.

Huang, Y., Ryu, Y., Jiang, C., Kimm, H., Kim, S., Kang, M., Shim, K., 2018. BESS-Rice: A remote sensing derived and biophysical process-based rice productivity simulation model. Agricultural and Forest Meteorology 256-257, 253-269. https://doi.org/10.1016/j.agrformet.2018.03.014

Jacquemoud, S., Baret, F., 1990. PROSPECT: A model of leaf optical properties spectra. Remote Sensing of Environment 34, 75-91.

Jacquemoud, S., Verhoef, W., Baret, F., Bacour, C., Zarco-Tejada, P.J., Asner, G.P., François, C., Ustin, S.L., 2009. PROSPECT+SAIL models: A review of use for vegetation characterization. Remote Sensing of Environment 113, S56-S66. https://doi.org/10.1016/j.rse.2008.01.026

Joiner, J., Yoshida, Y., Vasilkov, A.P., Yoshida, Y., Corp, L.A., Middleton, E.M., 2011. First observations of global and seasonal terrestrial chlorophyll fluorescence from space. Biogeosciences 8, 637-651. https://doi.org/10.5194/bg-8-637-2011

Joiner, J., Yoshida, Y., Zhang, Y., Duveiller, G., Jung, M., Lyapustin, A., Wang, Y., Tucker, C., 2018. Estimation of Terrestrial Global Gross Primary Production (GPP) with Satellite Data-Driven Models and Eddy Covariance Flux Data. Remote Sensing 10, 1346. https://doi.org/10.3390/rs10091346

Kasuya, E., 2019. On the use of $r$ and $r$ squared in correlation and regression. Ecological Research 34, 235236.

Kim, J., Ryu, Y., Jiang, C., Hwang, Y., 2019. Continuous observation of vegetation canopy dynamics using an integrated low-cost, near-surface remote sensing system. Agricultural and Forest Meteorology 264, 164-177. https://doi.org/10.1016/j.agrformet.2018.09.014 
Knyazikhin, Y., Schull, M.A., Stenberg, P., Mottus, M., Rautiainen, M., Yang, Y., Marshak, A., Latorre Carmona, P., Kaufmann, R.K., Lewis, P., Disney, M.I., Vanderbilt, V., Davis, A.B., Baret, F., Jacquemoud, S., Lyapustin, A., Myneni, R.B., 2013. Hyperspectral remote sensing of foliar nitrogen content. Proceedings of the National Academy of Sciences 110, E185-E192. https://doi.org/10.1073/pnas.1210196109

Köhler, P., Frankenberg, C., Magney, T.S., Guanter, L., Joiner, J., Landgraf, J., 2018. Global Retrievals of Solar-Induced Chlorophyll Fluorescence With TROPOMI: First Results and Intersensor Comparison to OCO-2. Geophysical Research Letters. https://doi.org/10.1029/2018GL079031

Kowalski, S., Sartore, M., Burlett, R., Berbigier, P., Loustau, D., 2003. The annual carbon budget of a French pine forest (Pinus pinaster) following harvest. Global Change Biology 9, 1051-1065. https://doi.org/10.1046/j.1365-2486.2003.00627.x

Li, Z., Zhang, Q., Li, J., Yang, X., Wu, Y., Zhang, Z., Wang, S., Wang, H., Zhang, Y., 2020. Solar-induced chlorophyll fluorescence and its link to canopy photosynthesis in maize from continuous ground $\begin{array}{llll}\text { measurements. Remote Sensing of Environment 236, } 111420 . & \text {. }\end{array}$ https://doi.org/10.1016/j.rse.2019.111420

Lichtenthaler, H.K., Buschmann, C., Rinderle, U., Schmuck, G., 1986. Application of chlorophyll fluorescence in ecophysiology. Radiation and Environmental Biophysics 25, 297-308. https://doi.org/10.1007/BF01214643

Liu, X., Guanter, L., Liu, L., Damm, A., Malenovský, Z., Rascher, U., Peng, D., Du, S., Gastellu-Etchegorry, J.P., 2018. Downscaling of solar-induced chlorophyll fluorescence from canopy level to photosystem level using a random forest model. Remote Sensing of Environment. https://doi.org/10.1016/j.rse.2018.05.035

Liu, X., Liu, L., 2018. Influence of the canopy BRDF characteristics and illumination conditions on the retrieval of solar-induced chlorophyll fluorescence. International Journal of Remote Sensing 39, 1782-1799. https://doi.org/10.1080/01431161.2017.1404165

Luo, X., Croft, H., Chen, J.M., He, L., Keenan, T.F., 2019. Improved estimates of global terrestrial photosynthesis using information on leaf chlorophyll content. Global Change Biology 25, 24992514. https://doi.org/10.1111/gcb.14624

Magney, T.S., Bowling, D.R., Logan, B.A., Grossmann, K., Stutz, J., Blanken, P.D., Burns, S.P., Cheng, R., Garcia, M.A., Köhler, P., Lopez, S., Parazoo, N.C., Raczka, B., Schimel, D., Frankenberg, C., 2019. Mechanistic evidence for tracking the seasonality of photosynthesis with solar-induced fluorescence. Proceedings of the National Academy of Sciences 201900278. https://doi.org/10.1073/pnas.1900278116

Marcolla, B., Cescatti, A., 2017. Geometry of the hemispherical radiometric footprint over plant canopies. Theoretical and Applied Climatology. https://doi.org/10.1007/s00704-017-2326-z

Meroni, M., Busetto, L., Colombo, R., Guanter, L., Moreno, J., Verhoef, W., 2010. Performance of Spectral Fitting Methods for vegetation fluorescence quantification. Remote Sensing of Environment 114, 363-374. https://doi.org/10.1016/j.rse.2009.09.010

Meroni, M., Colombo, R., 2006. Leaf level detection of solar induced chlorophyll fluorescence by means of a subnanometer resolution spectroradiometer. Remote Sensing of Environment 103, 438-448. https://doi.org/10.1016/j.rse.2006.03.016

Meroni, M., Rossini, M., Guanter, L., Alonso, L., Rascher, U., Colombo, R., Moreno, J., 2009. Remote sensing of solar-induced chlorophyll fluorescence: Review of methods and applications. Remote Sensing of Environment 113, 2037-2051. https://doi.org/10.1016/j.rse.2009.05.003

Miao, G., Guan, K., Yang, X., Bernacchi, C.J., Berry, J.A., DeLucia, E.H., Wu, J., Moore, C.E., Meacham, K., Cai, Y., Peng, B., Kimm, H., Masters, M.D., 2018. Sun-Induced Chlorophyll Fluorescence, Photosynthesis, and Light Use Efficiency of a Soybean Field from Seasonally Continuous 
Measurements. Journal of Geophysical Research: Biogeosciences 123, 610-623. https://doi.org/10.1002/2017JG004180

Migliavacca, M., Perez-Priego, O., Rossini, M., El-Madany, T.S., Moreno, G., van der Tol, C., Rascher, U., Berninger, A., Bessenbacher, V., Burkart, A., Carrara, A., Fava, F., Guan, J.-H., Hammer, T.W., Henkel, K., Juarez-Alcalde, E., Julitta, T., Kolle, O., Martín, M.P., Musavi, T., Pacheco-Labrador, J., Pérez-Burgueño, A., Wutzler, T., Zaehle, S., Reichstein, M., 2017. Plant functional traits and canopy structure control the relationship between photosynthetic $\mathrm{CO}_{2}$ uptake and far-red suninduced fluorescence in a Mediterranean grassland under different nutrient availability. New Phytologist. https://doi.org/10.1111/nph.14437

Mohammed, G.H., Colombo, R., Middleton, E.M., Rascher, U., van der Tol, C., Nedbal, L., Goulas, Y., PérezPriego, O., Damm, A., Meroni, M., Joiner, J., Cogliati, S., Verhoef, W., Malenovský, Z., GastelluEtchegorry, J.-P., Miller, J.R., Guanter, L., Moreno, J., Moya, I., Berry, J.A., Frankenberg, C., ZarcoTejada, P.J., 2019. Remote sensing of solar-induced chlorophyll fluorescence (SIF) in vegetation: 50 years of progress. Remote Sensing of Environment 231, 111177. https://doi.org/10.1016/j.rse.2019.04.030

Monteith, J.L., 1972. Solar Radiation and Productivity in Tropical Ecosystems. The Journal of Applied Ecology 9, 747. https://doi.org/10.2307/2401901

Monteith, J.L., Moss, C.J., 1977. Climate and the efficiency of crop production in Britain [and discussion]. Philosophical Transactions of the Royal Society of London B: Biological Sciences 281, 277-294.

Moore III, B., Crowell, S.M.R., Rayner, P.J., Kumer, J., O’Dell, C.W., O’Brien, D., Utembe, S., Polonsky, I., Schimel, D., Lemen, J., 2018. The Potential of the Geostationary Carbon Cycle Observatory (GeoCarb) to Provide Multi-scale Constraints on the Carbon Cycle in the Americas. Frontiers in Environmental Science 6. https://doi.org/10.3389/fenvs.2018.00109

Porcar-Castell, A., 2011. A high-resolution portrait of the annual dynamics of photochemical and nonphotochemical quenching in needles of Pinus sylvestris. Physiologia Plantarum 143, 139-153. https://doi.org/10.1111/j.1399-3054.2011.01488.x

Qiu, B., Chen, J.M., Ju, W., Zhang, Q., Zhang, Y., 2019. Simulating emission and scattering of solar-induced chlorophyll fluorescence at far-red band in global vegetation with different canopy structures. Remote Sensing of Environment 233, 111373. https://doi.org/10.1016/j.rse.2019.111373

R Core Team, 2012. R: A language and environment for statistical computing. R Foundation for Statistical Computing, Vienna, Austria. ISBN 3-900051-07-0, URL http://www.R-project.org/.

Raczka, B., Porcar-Castell, A., Magney, T., Lee, J.E., Köhler, P., Frankenberg, C., Grossmann, K., Logan, B.A., Stutz, J., Blanken, P.D., Burns, S.P., Duarte, H., Yang, X., Lin, J.C., Bowling, D.R., 2019. Sustained Non-Photochemical Quenching Shapes the Seasonal Pattern of Solar- Induced Fluorescence at a High-Elevation Evergreen Forest. Journal of Geophysical Research: Biogeosciences. https://doi.org/10.1029/2018JG004883

Reichstein, M., Falge, E., Baldocchi, D., Papale, D., Aubinet, M., Berbigier, P., Bernhofer, C., Buchmann, N., Gilmanov, T., Granier, A., Grunwald, T., Havrankova, K., Ilvesniemi, H., Janous, D., Knohl, A., Laurila, T., Lohila, A., Loustau, D., Matteucci, G., Meyers, T., Miglietta, F., Ourcival, J.-M., Pumpanen, J., Rambal, S., Rotenberg, E., Sanz, M., Tenhunen, J., Seufert, G., Vaccari, F., Vesala, T., Yakir, D., Valentini, R., 2005. On the separation of net ecosystem exchange into assimilation and ecosystem respiration: review and improved algorithm. Global Change Biology 11, 1424-1439. https://doi.org/10.1111/j.1365-2486.2005.001002.x

Ryu, Y., Berry, J.A., Baldocchi, D.D., 2019. What is global photosynthesis? History, uncertainties and opportunities. Remote Sensing of Environment 223, 95-114. https://doi.org/10.1016/j.rse.2019.01.016 
Ryu, Y., Jiang, C., Kobayashi, H., Detto, M., 2018. MODIS-derived global land products of shortwave radiation and diffuse and total photosynthetically active radiation at $5 \mathrm{~km}$ resolution from 2000 . Remote Sensing of Environment 204, 812-825. https://doi.org/10.1016/j.rse.2017.09.021

Schaepman-Strub, G., Schaepman, M.E., Painter, T.H., Dangel, S., Martonchik, J.V., 2006. Reflectance quantities in optical remote sensing-definitions and case studies. Remote Sensing of Environment 103, 27-42. https://doi.org/10.1016/j.rse.2006.03.002

Sun, Y., Frankenberg, C., Jung, M., Joiner, J., Guanter, L., Köhler, P., Magney, T., 2018. Overview of SolarInduced chlorophyll Fluorescence (SIF) from the Orbiting Carbon Observatory-2: Retrieval, crossmission comparison, and global monitoring for GPP. Remote Sensing of Environment. https://doi.org/10.1016/j.rse.2018.02.016

Sun, Y., Frankenberg, C., Wood, J.D., Schimel, D.S., Jung, M., Guanter, L., Drewry, D.T., Verma, M., PorcarCastell, A., Griffis, T.J., Gu, L., Magney, T.S., Köhler, P., Evans, B., Yuen, K., 2017. OCO-2 advances photosynthesis observation from space via solar-induced chlorophyll fluorescence. Science 358, eaam5747. https://doi.org/10.1126/science.aam5747

Tagliabue, G., Panigada, C., Dechant, B., Baret, F., Cogliati, S., Colombo, R., Migliavacca, M., Rademske, P., Schickling, A., Schüttemeyer, D., Verrelst, J., Rascher, U., Ryu, Y., Rossini, M., 2019. Exploring the spatial relationship between airborne-derived red and far-red sun-induced fluorescence and process-based GPP estimates in a forest ecosystem. Remote Sensing of Environment 231, 111272. https://doi.org/10.1016/j.rse.2019.111272

van der Tol, C., Berry, J.A., Campbell, P.K.E., Rascher, U., 2014. Models of fluorescence and photosynthesis for interpreting measurements of solar-induced chlorophyll fluorescence. Journal of Geophysical Research: Biogeosciences 119, 2312-2327. https://doi.org/10.1002/2014JG002713

Wieneke, S., Ahrends, H., Damm, A., Pinto, F., Stadler, A., Rossini, M., Rascher, U., 2016. Airborne based spectroscopy of red and far-red sun-induced chlorophyll fluorescence: Implications for improved estimates of gross primary productivity. Remote Sensing of Environment 184, 654-667. https://doi.org/10.1016/j.rse.2016.07.025

Wieneke, S., Burkart, A., Cendrero-Mateo, M.P., Julitta, T., Rossini, M., Schickling, A., Schmidt, M., Rascher, U., 2018. Linking photosynthesis and sun-induced fluorescence at sub-daily to seasonal scales. Remote Sensing of Environment 219, 247-258. https://doi.org/10.1016/j.rse.2018.10.019

Yang, H., Yang, X., Zhang, Y., Heskel, M.A., Lu, X., Munger, J.W., Sun, S., Tang, J., 2017. Chlorophyll fluorescence tracks seasonal variations of photosynthesis from leaf to canopy in a temperate forest. Global Change Biology 23, 2874-2886. https://doi.org/10.1111/gcb.13590

Yang, K., Ryu, Y., Dechant, B., Berry, J.A., Hwang, Y., Jiang, C., Kang, M., Kim, J., Kimm, H., Kornfeld, A., Yang, X., 2018. Sun-induced chlorophyll fluorescence is more strongly related to absorbed light than to photosynthesis at half-hourly resolution in a rice paddy. Remote Sensing of Environment 216, 658-673. https://doi.org/10.1016/j.rse.2018.07.008

Yang, P., van der Tol, C., 2018. Linking canopy scattering of far-red sun-induced chlorophyll fluorescence with reflectance. Remote Sensing of Environment 209, 456-467. https://doi.org/10.1016/j.rse.2018.02.029

Yang, X., Shi, H., Stovall, A., Guan, K., Miao, G., Zhang, Yongguang, Zhang, Yao, Xiao, X., Ryu, Y., Lee, J.-E., 2018. FluoSpec 2-An Automated Field Spectroscopy System to Monitor Canopy Solar-Induced Fluorescence 18.

Yang, X., Tang, J., Mustard, J.F., Lee, J.-E., Rossini, M., Joiner, J., Munger, J.W., Kornfeld, A., Richardson, A.D., 2015. Solar-induced chlorophyll fluorescence that correlates with canopy photosynthesis on diurnal and seasonal scales in a temperate deciduous forest: Fluorescence and photosynthesis. Geophysical Research Letters 42, 2977-2987. https://doi.org/10.1002/2015GL063201 
Zeng, Y., Badgley, G., Dechant, B., Ryu, Y., Chen, M., Berry, J.A., 2019. A practical approach for estimating the escape ratio of solar-induced chlorophyll fluorescence. Remote Sensing of Environment 232, 111209. https://doi.org/10.1016/j.rse.2019.05.028.

Zhang, Yongguang, Guanter, L., Berry, J.A., van der Tol, C., Yang, X., Tang, J., Zhang, F., 2016. Model-based analysis of the relationship between sun-induced chlorophyll fluorescence and gross primary production for remote sensing applications. Remote Sensing of Environment 187, 145-155. https://doi.org/10.1016/j.rse.2016.10.016

Zhang, Yongguang, Guanter, L., Joiner, J., Song, L., Guan, K., 2018. Spatially-explicit monitoring of crop photosynthetic capacity through the use of space-based chlorophyll fluorescence data. Remote Sensing of Environment 210, 362-374. https://doi.org/10.1016/j.rse.2018.03.031

Zhang, Yao, Joiner, J., Alemohammad, S.H., Zhou, S., Gentine, P., 2018a. A global spatially Continuous Solar Induced Fluorescence (CSIF) dataset using neural networks. Biogeosciences Discussions 1-34. https://doi.org/10.5194/bg-2018-255

Zhang, Yao, Xiao, X., Jin, C., Dong, J., Zhou, S., Wagle, P., Joiner, J., Guanter, L., Zhang, Yongguang, Zhang, G., Qin, Y., Wang, J., Moore, B., 2016. Consistency between sun-induced chlorophyll fluorescence and gross primary production of vegetation in North America. Remote Sensing of Environment 183, 154-169. https://doi.org/10.1016/j.rse.2016.05.015

Zhang, Yao, Xiao, X., Zhang, Yongguang, Wolf, S., Zhou, S., Joiner, J., Guanter, L., Verma, M., Sun, Y., Yang, X., Paul-Limoges, E., Gough, C.M., Wohlfahrt, G., Gioli, B., van der Tol, C., Yann, N., Lund, M., de Grandcourt, A., 2018b. On the relationship between sub-daily instantaneous and daily total gross primary production: Implications for interpreting satellite-based SIF retrievals. Remote Sensing of Environment 205, 276-289. https://doi.org/10.1016/j.rse.2017.12.009

Zoogman, P., Liu, X., Suleiman, R.M., Pennington, W.F., Flittner, D.E., Al-Saadi, J.A., Hilton, B.B., Nicks, D.K., Newchurch, M.J., Carr, J.L., Janz, S.J., Andraschko, M.R., Arola, A., Baker, B.D., Canova, B.P., Chan Miller, C., Cohen, R.C., Davis, J.E., Dussault, M.E., Edwards, D.P., Fishman, J., Ghulam, A., González Abad, G., Grutter, M., Herman, J.R., Houck, J., Jacob, D.J., Joiner, J., Kerridge, B.J., Kim, J., Krotkov, N.A., Lamsal, L., Li, C., Lindfors, A., Martin, R.V., McElroy, C.T., McLinden, C., Natraj, V., Neil, D.O., Nowlan, C.R., O'Sullivan, E.J., Palmer, P.I., Pierce, R.B., Pippin, M.R., Saiz-Lopez, A., Spurr, R.J.D., Szykman, J.J., Torres, O., Veefkind, J.P., Veihelmann, B., Wang, H., Wang, J., Chance, K., 2017. Tropospheric emissions: Monitoring of pollution (TEMPO). Journal of Quantitative Spectroscopy and Radiative Transfer 186, 17-39. https://doi.org/10.1016/j.jqsrt.2016.05.008 